INSTITUT NATIONAL DE LA STATISTIQUE ET DES ETUDES ECONOMIQUES

Série des Documents de Travail du CREST

(Centre de Recherche en Economie et Statistique)

\author{
$n^{\circ}$ 2005-41 \\ International Money and Stock \\ Market Contingent Claims \\ C. GOURIEROUX \\ A. MONFORT 2 \\ R. SUFANA ${ }^{3}$
}

Les documents de travail ne reflètent pas la position de l'INSEE et n'engagent que leurs auteurs.

Working papers do not reflect the position of INSEE but only the views of the authors.

\footnotetext{
${ }^{1}$ CREST, CEPREMAP (Paris) and University of Toronto..

2 CREST and CNAM.

${ }^{3}$ University of Toronto.
} 


\section{International Money and Stock Market Contingent Claims}

Christian Gouriéroux ${ }^{1}$, Alain Monfort ${ }^{2}$, and Razvan Sufana ${ }^{3}$

March 2005

1 CREST, CEPREMAP and University of Toronto.

2 CREST and CNAM.

3 University of Toronto. 
International Money and Stock Market Contingent Claims

\begin{abstract}
We develop a unified approach with closed-form solutions for pricing bonds, stocks, currencies and their derivatives. The specification assumes a fundamental risk factor represented by a stochastic positive definite matrix following a Wishart autoregressive (WAR) process. By assuming a volatility-in-mean specification for the domestic stock returns and the relative changes of the exchange rates, and a domestic stochastic discount factor exponential affine with respect to the fundamental risk, it is possible to derive closed form solutions for the term structures of interest rates and for the risk neutral probabilities. In particular:

i) The domestic and foreign term structures are jointly affine and correspond to Wishart quadratic term structures, which can ensure the positivity of interest rates;

ii) In this framework where the stock price follows a model with stochastic volatility we obtain explicit or quasi-explicit formulas for futures and forward contracts, swaps and options; this extends results by Heston (1993) and Ball, Roma (1994).
\end{abstract}

Keywords : Quadratic Term Structure, Exchange Rates, Stochastic Volatility Model, Wishart (WAR) Process, Futures and Forward Contracts.

JEL number : G12, G13. 


\section{Introduction}

The major part of the financial literature considers separately the problems of bond and stock pricing. For instance there exists a large literature on the term structure of interest rates (see e.g. Martellini, Priaulet (2001), Dai, Singleton (2003) for surveys). The so-called affine term structure models introduced by Duffie and Kan (1996) provide a specification which is easily implementable and sufficiently flexible to fit the available bond data. In parallel the models for stock pricing generally assume a constant riskfree rate and try to reproduce the basic implication of the CAPM, that is the positive relationship between expected return and volatility due to the existence of a risk premium (Merton (1973)).

From a modelling viewpoint, coherent models for bonds and stocks can also be used to price commodity derivatives (futures and futures options) with a stochastic term structure, or to analyze term structures and exchange rates in an international framework. They are often presented in one of these ways in the literature. i) For instance, based on preliminary works on the term structure of commodity derivative prices ${ }^{4}$, several authors have considered either stochastic spot price for the commodity and stochastic convenience yield (Jarrow (1987), Gibson, Schwartz (1990)), or stochastic spot price, convenience yield and interest rate (Schwartz (1997), Hilliard, Reis (1998), Miltersen, Schwartz (1998), Jarrow, Turnbull (1998), (2000)). ii) Symmetrically Grabbe (1983), Amin, Jarrow (1991), Brace, Musiela (1997) considered derivative pricing in an international economy from both domestic and foreign perspectives. In particular, coherent approaches with closed form pricing formulas have been developed by Miltersen, Schwartz (1998) for commodity markets and by Amin, Jarrow (1991), Brace, Musiela (1997) for international markets. They are all based on the Gaussian Heath-Jarrow-Morton model (Heath, Jarrow, Morton (1992)). Despite the interest of the derived closed-form formulas, these approaches are

4 See Ramaswamy, Sundaresan (1985), Cortazar, Schwartz (1994), Amin, Ng, Pirrong (1995). 
valid under the restrictive assumption of constant or deterministic volatility ${ }^{5}$. Moreover they do not ensure the positivity of interest rates.

The present paper is in the spirit of the later literature. Its aim is to encompass the affine term structure models and the standard models for stock pricing in a multicountry framework, providing simple closed-form pricing formulas. Compared to Amin, Jarrow (1991) and Miltersen, Schwartz (1998), the Wishart quadratic term structure model is taken as a basis, instead of the Heath, Jarrow, Morton' model. The approach still provides closed form pricing formulas and appears more flexible. For instance i) stochastic volatilities and covolatilities are allowed; ii) stochastic risk premia of CAPM type can be introduced in the return equations; iii) the positivity of interest rates is easy to characterize by means of appropriate parameter restrictions; iv) Last, but not least, the coherency exists between the historical and risk-neutral distributions ${ }^{6}$. Whereas the risk-neutral analysis is important for derivative pricing, the historical analysis is needed for parameter estimation based on time series observations and for the determination of Values at Risk (VaR). In Section 2 we introduce a factor model, where the factors measure a fundamental multivariate risk which is represented by a stochastic symmetric positive definite matrix. These factors influence i) the stochastic discount factor (sdf) of the domestic country which drives the level of the domestic state prices, ii) the stock prices (domestic and foreign market indexes) by means of a stochastic variance-in-mean model, and iii) the relative changes of the exchange rates. By selecting a domestic sdf which is an exponential affine function of the factor and a factor satisfying a Wishart autoregressive (WAR) process (Gourieroux, Sufana (2003), (2004), Gourieroux, Jasiak, Sufana (2004)), we derive in Section 3 affine domestic and foreign term structures. The relationship be-

5 See Section 4 in Miltersen, Schwartz (1998), Assumption 7 in Amin, Jarrow (1991), Section 2 in Brace, Musiela (1997).

6 In previous papers [see e. g. Amin, Jarrow (1991), Miltersen, Schwartz (1998)], the analysis is only done in the risk-neutral world. 
tween the domestic term structure, the foreign term structure and the exchange rate is illustrated by numerical examples with realistic parameter values. In particular we show the flexibility of the specification in producing various patterns of both the domestic and foreign term structures. As well-known, it is important to distinguish between forward and futures contracts when the interest rates are stochastic. Clearly in an international economy at least one of the domestic and foreign interest rates is stochastic, whenever the exchange rate is not deterministic. Futures and forward contracts written on market indexes or exchange rates are explicitly priced in Section 4. Similarly we consider in Section 5 closed-form pricing formulas for swaps and quasi-explicit formulas for options written on foreign indexes, futures or forward contracts, and zero-coupon bonds. Section 6 concludes. Proofs are gathered in appendices.

\section{The international economy}

\subsection{The assumptions}

Let us consider $n$ countries, indexed by $j=1, \ldots, n$. Country 1 is the domestic country, used as a reference for defining the different variables of interest. The primitive variables are: i) the exchange rates between the currencies of countries $j$ and 1 , that is the price of one unit of currency $j$ denominated in currency 1 , with relative change denoted by $r_{j \mid 1, t}$, $j=1, \ldots, n$. Note that $r_{1 \mid 1, t}=0$. ii) the domestic denominated market indexes with geometric returns denoted by $y_{j \mid 1, t}, j=1, \ldots, n . y_{1 \mid 1, t}$ corresponds to a standard market return, whereas $y_{j \mid 1, t}, j=2, \ldots, n$ corresponds to the return of a quanto written on a foreign index ${ }^{7}$.

\footnotetext{
7 Quantos are contingent claims with a nominal "payoff" denominated in one currency, but paid in another currency. A typical example is the Nikkei equity index option with the yen Nikkei return paid in dollars [Amin, Bodurtha (1995)].
} 
As now usual in modern finance (see e.g. the survey by Ferson (2003)), the model assumes a stochastic discount factor for country 1, that is a domestic sdf, which can be used to price all assets of interest, that are bonds, stocks and derivatives written on bonds, stocks, or currencies, whenever their prices and payoffs are denominated in currency 1. To get tractable specifications, we consider the following set of assumptions written in discrete time.

Assumption A.1 : (Information set) The information of the investors includes a measure of the fundamental risk, represented by a $(L, L)$ stochastic symmetric positive definite matrix $\Sigma_{t}$, and some specific risks $\varepsilon_{j \mid 1, t}, j=1, \ldots, 2 n$, associated with the $n$ currencies and the $n$ market indexes of interest.

\section{Assumption A.2 : (Dynamics of exchange rates and domestic market returns)}

i) The relative changes of the exchange rates can be written $\operatorname{as}^{8}$ :

$$
r_{j \mid 1, t+1}=d_{j \mid 1}+\operatorname{Tr}\left(D_{j \mid 1}^{0} \Sigma_{t}\right)+\operatorname{Tr}\left(D_{j \mid 1} \Sigma_{t+1}\right)+\varepsilon_{j \mid 1, t+1}, \quad j=1, \ldots, n,
$$

where $D_{j, 1}^{0}, D_{j \mid 1}$ are $(L, L)$ symmetric matrices, $d_{j \mid 1}$ is an intercept, and $d_{1 \mid 1}=0, D_{1 \mid 1}^{0}=0$, $D_{1 \mid 1}=0, \varepsilon_{1 \mid 1, t+1}=0$, by the choice of the domestic country 1 .

ii) The market returns can be written as:

$$
y_{j \mid 1, t+1}=f_{j \mid 1}+\operatorname{Tr}\left(F_{j \mid 1}^{0} \Sigma_{t}\right)+\operatorname{Tr}\left(F_{j \mid 1} \Sigma_{t+1}\right)+\varepsilon_{j+n \mid 1, t+1}, \quad j=1, \ldots, n,
$$

where $F_{j \mid 1}^{0}, F_{j \mid 1}$ are $(L, L)$ symmetric matrices and $f_{j \mid 1}$ an intercept.

iii) The error terms $\varepsilon_{j \mid 1, t+1}, j=1, \ldots, 2 n$, are such that : $\varepsilon_{\mid 1, t+1}=\left(\varepsilon_{1 \mid 1, t+1}, \ldots, \varepsilon_{2 n \mid 1, t+1}\right)^{\prime}$ is multivariate Gaussian conditional on ${ }^{9} \underline{\Sigma_{t+1}}, \underline{\varepsilon_{\mid 1, t}}$, with zero-mean and a variance-

$8 \operatorname{Tr}$ denotes the trace of a square matrix, that is the sum of its diagonal elements. Given two symmetric matrices $D$ and $\Sigma$, we get: $\operatorname{Tr}(D \Sigma)=\sum_{i=1}^{L} \sum_{j=1}^{L} d_{i j} \sigma_{i j}$. Thus $\operatorname{Tr}(D \Sigma)$ is simply a convenient notation for representing a linear combination of elements of $\Sigma$.

$9 \underline{\Sigma_{t+1}}$ denotes the set of values $\Sigma_{t+1}, \Sigma_{t}, \Sigma_{t-1}, \ldots$, prior to date $t+1$. 
covariance matrix $A_{1}^{\prime} \Sigma_{t+1} A_{1}$, where $A_{1}$ is a matrix of dimension $(L, 2 n)$ with a first column equal to zero.

The terms $\operatorname{Tr}\left(F_{j \mid 1} \Sigma_{t+1}\right), \operatorname{Tr}\left(F_{j \mid 1}^{0} \Sigma_{t}\right), \operatorname{Tr}\left(D_{j \mid 1}^{0} \Sigma_{t}\right), \operatorname{Tr}\left(D_{j \mid 1} \Sigma_{t+1}\right)$ included in the drifts can be seen as risk premia. For the domestic market return $y_{1 \mid 1, t+1}$, a positive risk premium is expected. However it has to be noted that the effect of risk passes through both the current and lagged values of $\Sigma$. We can expect that the risk premium is an increasing function of the expected volatility and a decreasing function of the surprise on volatility, that is ${ }^{10} \operatorname{Tr}\left(F_{1 \mid 1} \Sigma_{t+1}\right)<0, \operatorname{Tr}\left[\left(F_{1 \mid 1}+F_{1 \mid 1}^{0}\right) \Sigma_{t}\right]>0$. This is the so-called volatility feedback (see Bekaert, $\mathrm{Wu}(2000)$ ). It is easily checked that $\operatorname{Tr}(F \Sigma)$ for instance is positive if ${ }^{11}$ $F$ is a symmetric positive semidefinite matrix. Thus we expect $F_{1 \mid 1} \ll 0, F_{1 \mid 1}+F_{1 \mid 1}^{0} \gg 0$. We expect similar parameter sign conditions for all market returns expressed in their own money. Since:

$$
\begin{aligned}
y_{j \mid j, t+1} & =y_{j \mid 1, t+1}-r_{j \mid 1, t+1} \\
& =f_{j \mid 1}-d_{j \mid 1}+\operatorname{Tr}\left[\left(F_{j \mid 1}^{0}-D_{j \mid 1}^{0}\right) \Sigma_{t}\right]+\operatorname{Tr}\left[\left(F_{j \mid 1}-D_{j \mid 1}\right) \Sigma_{t+1}\right]+\varepsilon_{j+n \mid 1, t+1}-\varepsilon_{j \mid 1, t+1}
\end{aligned}
$$

these expected conditions are:

$$
F_{j \mid 1} \ll D_{j \mid 1}, F_{j \mid 1}+F_{j \mid 1}^{0} \gg D_{j \mid 1}+D_{j \mid 1}^{0}, \forall j,
$$

where $F \gg D$ means that $F-D$ is symmetric positive semidefinite.

When these inequalities are satisfied, the long term risk premia on market returns expressed in their own currencies increase when the fundamental risk increases (in the sense

10 Assuming volatility persistence.

11 Let us consider a symmetric positive semidefinite matrix $F$. Since $F$ can be decomposed as $F=\sum_{i=1}^{L} a_{i} a_{i}^{\prime}$, where $a_{i}, i=1, \ldots, L$ is a $L$-dimensional vector, we get:

$$
\operatorname{Tr}\left(F \Sigma_{t}\right)=\operatorname{Tr}\left(\sum_{i=1}^{L} a_{i} a_{i}^{\prime} \Sigma_{t}\right)=\sum_{i=1}^{L} \operatorname{Tr}\left(a_{i} a_{i}^{\prime} \Sigma_{t}\right)=\sum_{i=1}^{L} a_{i}^{\prime} \Sigma_{t} a_{i}
$$

by commuting within the trace. Thus $\operatorname{Tr}\left(F \Sigma_{t}\right) \geq 0$, since $\Sigma_{t}$ is positive definite. 
of symmetric matrices) $)^{12}$.

Assumption A.3 : (Domestic stochastic discount factor) The stochastic discount factor (sdf) for country 1 and period $(t, t+1)$ can be written as:

$$
M_{1, t, t+1}=\exp \left\{c_{1}+\operatorname{Tr}\left(C_{1}^{0} \Sigma_{t}\right)+\operatorname{Tr}\left(C_{1} \Sigma_{t+1}\right)+\gamma_{1}^{\prime} \varepsilon_{\mid 1, t+1}\right\}
$$

where $C_{1}^{0}, C_{1}$ are $(L, L)$ symmetric matrices, $c_{1}$ is an intercept, $\gamma_{1}$ is a $(2 n, 1)$ vector.

Thus the domestic sdf is an exponential affine function of both the fundamental risk and idiosyncratic factors. This exponential affine functional form will facilitate further computations (see e.g. Yao (2001), Dijkstra, Yao (2002), Gourieroux, Monfort (2005)). The matrices $C_{1}^{0}$ and $C_{1}^{0}+C_{1}$ are expected to be positive semidefinite and negative semidefinite, respectively, to represent the volatility feedback on state prices. Indeed under this condition the state prices diminish when the fundamental risk increases, whereas a surprise effect is introduced. Since the sdf in currency $j$ (that is the domestic sdf of country $j$ ) is:

$$
\begin{aligned}
M_{j, t, t+1} & =M_{1, t, t+1} \exp r_{j \mid 1, t+1} \\
& =\exp \left\{c_{1}+d_{j \mid 1}+\operatorname{Tr}\left[\left(C_{1}^{0}+D_{j \mid 1}^{0}\right) \Sigma_{t}\right]+\operatorname{Tr}\left[\left(C_{1}+D_{j \mid 1}\right) \Sigma_{t+1}\right]+\gamma_{1}^{\prime} \varepsilon_{\mid 1, t+1}+\varepsilon_{j \mid 1, t+1}\right\}
\end{aligned}
$$

it is expected that:

$$
C_{1}+D_{j \mid 1} \gg 0, \quad C_{1}^{0}+C_{1}+D_{j \mid 1}^{0}+D_{j \mid 1} \ll 0, \quad j=1, \ldots, n
$$

Assumption A.4 : (Factor dynamics) The fundamental risk measure $\left(\Sigma_{t}\right)$ follows a Wishart autoregressive (WAR) process, with conditional Laplace transform:

$$
E\left[\exp \operatorname{Tr}\left(\Gamma \Sigma_{t+1}\right) \mid \underline{\Sigma_{t}}\right]=\frac{\exp \operatorname{Tr}\left[M^{\prime} \Gamma(I d-2 \Omega \Gamma)^{-1} M \Sigma_{t}\right]}{[\operatorname{det}(I d-2 \Omega \Gamma)]^{K / 2}},
$$

where $M$ is a $(L, L)$ matrix of latent autoregressive coefficients, $\Omega$ is a $(L, L)$ matrix of

12 Let us consider two levels of risks $\Sigma_{1} \gg \Sigma_{2}$, say. Suppose that the risk premium is equal to $\operatorname{Tr}(F \Sigma)$, where $F$ is positive definite. Since $\Sigma_{1}-\Sigma_{2} \gg 0$, we know that $\operatorname{Tr}\left[F\left(\Sigma_{1}-\Sigma_{2}\right)\right] \geq 0$, or equivalently $\operatorname{Tr}\left(F \Sigma_{1}\right) \geq$ $\operatorname{Tr}\left(F \Sigma_{2}\right)$; therefore the risk premium increases with $\Sigma$. 
latent volatility and $K$ a positive degree of freedom. $\Gamma$ is a $(L, L)$ matrix of real or complex elements and the Laplace transform exists whenever $\|2 \Omega \Gamma\|<1$.

The Wishart process is the direct extension of the Cox-Ingersoll-Ross process to multivariate "volatility-covolatility" matrices and feature the mean-reverting property usually observed in practice. The conditional Laplace transform characterizes its transition distribution which is a noncentral Wishart distribution (see Gourieroux (2004)). Since the conditional Laplace transform is an exponential affine function of $\Sigma_{t}$, the Wishart process is a special case of affine process. ${ }^{13}$

The dynamic specifications introduced for market returns and relative changes of exchange rates imply restrictions on the joint marginal and conditional distributions of the variables. For instance the marginal distribution of the relative change of exchange rate $r_{j \mid 1, t+1}$ is easily characterized by its marginal Laplace transform:

$$
\begin{aligned}
& E \exp \left(u r_{j \mid 1, t+1}\right) \\
= & E \exp \left[u d_{j \mid 1}+\operatorname{Tr}\left(u D_{j \mid 1}^{0} \Sigma_{t}\right)+\operatorname{Tr}\left(u D_{j \mid 1} \Sigma_{t+1}\right)+u \varepsilon_{j \mid 1, t+1}\right] \\
= & E \exp \left[u d_{j \mid 1}+\operatorname{Tr}\left(u D_{j \mid 1}^{0} \Sigma_{t}\right)+\operatorname{Tr}\left(\left(u D_{j \mid 1}+\frac{1}{2} u^{2} A_{1 j} A_{1 j}^{\prime}\right) \Sigma_{t+1}\right)\right] \\
& \left(\text { by integrating conditional on } \Sigma_{t}, \Sigma_{t+1}\right) \\
= & \exp \left(u d_{j \mid 1}\right) \operatorname{det}\left[I d-2 \Omega\left(u D_{j \mid 1}+\frac{1}{2} u^{2} A_{1 j} A_{1 j}^{\prime}\right)\right]^{-K / 2} \\
& E\left\{\exp \operatorname{Tr}\left[\left(u D_{j \mid 1}^{0}+M^{\prime}\left(u D_{j \mid 1}+\frac{1}{2} u^{2} A_{1 j} A_{1 j}^{\prime}\right)\left(I d-2 \Omega\left(u D_{j \mid 1}+\frac{1}{2} u^{2} A_{1 j} A_{1 j}^{\prime}\right)\right)^{-1} M\right) \Sigma_{t}\right]\right\} \\
& \left(\operatorname{by} \operatorname{integrating} \operatorname{conditional~on~} \Sigma_{t}\right) \\
= & \exp \left(u d_{j \mid 1}\right) \operatorname{det}\left[I d-2 \Omega\left(u D_{j \mid 1}+\frac{1}{2} u^{2} A_{1 j} A_{1 j}^{\prime}\right)\right]^{-K / 2} \\
& \operatorname{det}\left[I d-2 \Omega(\infty)\left(u D_{j \mid 1}^{0}+M^{\prime}\left(u D_{j \mid 1}+\frac{1}{2} u^{2} A_{1 j} A_{1 j}^{\prime}\right)\left(I d-2 \Omega\left(u D_{j \mid 1}+\frac{1}{2} u^{2} A_{1 j} A_{1 j}^{\prime}\right)\right)^{-1} M\right)\right]^{-K / 2},
\end{aligned}
$$

by integrating with respect to $\Sigma_{t}$ [see Gourieroux, Jasiak, Sufana (2004)], where $A_{1 j}$

\footnotetext{
13 Also called Compound Autoregressive (CAR) processes when they are considered in discrete time [Darolles, Gourieroux, and Jasiak (2005)].
} 
denotes the $j$ th column of $A_{1}$ and $\Omega(\infty)$ is the solution of the equation:

$$
\Omega(\infty)=M \Omega(\infty) M^{\prime}+\Omega
$$

The first and second order moments are deduced by considering the second order expansion of the log-Laplace transform.

Finally note that the basic set of assumptions A1-A4 differs from the basic sets introduced in the previous literature for coherent modelling. i) They are written under the historical distribution in order to be able to derive both the historical and risk-neutral dynamics; ii) A Wishart factor process is introduced to get a quadratic term structure model compatible with the observed positivity of interest rates; iii) They focus on the domestic sdf and not on the domestic and foreign forward term structures as needed in the Heath-Jarrow-Morton approach. The forward term structure dynamics will be derived as a byproduct in Section 3 .

\subsection{An invariance property by change of currency}

Up to now the dynamics of exchange rates, bonds and market returns have been defined with reference to country 1 . However we can adopt a foreign trader perspective and choose the currency of another country $l$, say, as a new numeraire. The relative changes of the exchange rates, the market returns and the sdf are modified in the following way (with clear notations):

$$
\begin{aligned}
r_{j \mid l, t+1} & =r_{j \mid 1, t+1}-r_{l \mid 1, t+1}, j=1, \ldots, n \\
y_{j \mid l, t+1} & =y_{j \mid 1, t+1}-r_{l \mid 1, t+1}, j=1, \ldots, n \\
M_{l, t, t+1} & =M_{1, t, t+1} \exp r_{l \mid 1, t+1}=M_{1, t, t+1} M_{l \mid 1, t, t+1}, \text { say. }
\end{aligned}
$$

Thus we deduce:

$$
\begin{aligned}
r_{j \mid l, t+1} & =d_{j \mid 1}-d_{l \mid 1}+\operatorname{Tr}\left[\left(D_{j \mid 1}^{0}-D_{l \mid 1}^{0}\right) \Sigma_{t}\right]+\operatorname{Tr}\left[\left(D_{j \mid 1}-D_{l \mid 1}\right) \Sigma_{t+1}\right]+\varepsilon_{j \mid 1, t+1}-\varepsilon_{l \mid 1, t+1} \\
& =d_{j \mid l}+\operatorname{Tr}\left(D_{j \mid l}^{0} \Sigma_{t}\right)+\operatorname{Tr}\left(D_{j \mid l} \Sigma_{t+1}\right)+\varepsilon_{j \mid l, t+1}
\end{aligned}
$$


where

$$
d_{j \mid l}=d_{j \mid 1}-d_{l \mid 1}, D_{j \mid l}^{0}=D_{j \mid 1}^{0}-D_{l \mid 1}^{0}, \quad D_{j \mid l}=D_{j \mid 1}-D_{l \mid 1}, \varepsilon_{j \mid l, t+1}=\varepsilon_{j \mid 1, t+1}-\varepsilon_{l \mid 1, t+1}
$$

Note that $\varepsilon_{j \mid j, t+1}=0, \forall j=1, \ldots, n$ and $\varepsilon_{j \mid l, t+1}=-\varepsilon_{l \mid j, t+1} \forall j, l \in\{1, \ldots, n\}$.

Similarly we get:

$$
\begin{aligned}
y_{j \mid l, t+1} & =f_{j \mid 1}-d_{l \mid 1}+\operatorname{Tr}\left[\left(F_{j \mid 1}^{0}-D_{l \mid 1}^{0}\right) \Sigma_{t}\right)+\operatorname{Tr}\left[\left(F_{j \mid 1}-D_{l \mid 1}\right) \Sigma_{t+1}+\varepsilon_{j+n \mid 1, t+1}-\varepsilon_{l \mid 1, t+1}\right. \\
& =f_{j \mid l}+\operatorname{Tr}\left(F_{j \mid l}^{0} \Sigma_{t}\right)+\operatorname{Tr}\left(F_{j \mid l} \Sigma_{t+1}\right)+\varepsilon_{j+n \mid l, t+1}
\end{aligned}
$$

where

$$
f_{j \mid l}=f_{j \mid 1}-d_{l \mid 1}, F_{j \mid l}^{0}=F_{j \mid 1}^{0}-D_{l \mid 1}^{0}, F_{j \mid l}=F_{j \mid 1}-D_{l \mid 1}, \varepsilon_{j+n \mid l, t+1}=\varepsilon_{j+n \mid 1, t+1}-\varepsilon_{l \mid 1, t+1} .
$$

Finally the new sdf is given by:

$$
\begin{aligned}
M_{l, t, t+1} & =\exp \left\{\left(c_{1}+d_{l \mid 1}\right)+\operatorname{Tr}\left[\left(C_{1}^{0}+D_{l \mid 1}^{0}\right) \Sigma_{t}\right]+\operatorname{Tr}\left[\left(C_{1}+D_{l \mid 1}\right) \Sigma_{t+1}\right]+\gamma_{1}^{\prime} \varepsilon_{\mid 1, t+1}+\varepsilon_{l \mid 1, t+1}\right\} \\
& =\exp \left[c_{l}+\operatorname{Tr}\left(C_{l}^{0} \Sigma_{t}\right)+\operatorname{Tr}\left(C_{l} \Sigma_{t+1}\right)+\gamma_{l}^{\prime} \varepsilon_{\mid l, t+1}\right]
\end{aligned}
$$

where

$$
\begin{gathered}
c_{l}=c_{1}+d_{l \mid 1}, C_{l}^{0}=C_{1}^{0}+D_{l \mid 1}^{0}, C_{l}=C_{1}+D_{l \mid 1}, \\
\gamma_{l}^{\prime} \varepsilon_{\mid l, t+1}=\left[\gamma_{1}^{\prime}\left[I d-e e_{1}^{\prime}\right]-e_{1}^{\prime}\right] \varepsilon_{\mid l, t+1},
\end{gathered}
$$

where $e=(1, \ldots, 1)^{\prime}$ and $e_{1}$ denotes the vector of dimension $2 n$ with zero components except the first which is equal to one.

Since $\varepsilon_{1 \mid 1, t+1}=0$, the component $\gamma_{11}$ can be arbitrary and an identification constraint for $\gamma_{1}$ is : $\gamma_{1}^{\prime} e=-1$. Under this identifying restriction, the last equality becomes:

$$
\left(\gamma_{l}^{\prime}-\gamma_{1}^{\prime}\right) \varepsilon_{\mid l, t+1}=0
$$

Thus we can choose: $\gamma_{l}=\gamma_{1}$, since $\gamma_{l l}$ is arbitrary because of $\varepsilon_{l \mid l, t+1}=0$.

Finally note that the new innovation $\varepsilon_{\mid l, t+1}$ is still conditionally Gaussian, with zeromean. Its variance-covariance matrix is:

$$
V_{t}\left(\varepsilon_{\mid l, t+1}\right)=V_{t}\left[\varepsilon_{\mid 1, t+1}-e e_{l}^{\prime} \varepsilon_{\mid 1, t+1}\right]
$$




$$
\begin{aligned}
& =V_{t}\left[\left(I d-e e_{l}^{\prime}\right) \varepsilon_{\mid 1, t+1}\right] \\
& =A_{l}^{\prime} \Sigma_{t+1} A_{l},
\end{aligned}
$$

where $A_{l}^{\prime}=\left[I d-e e_{l}^{\prime}\right] A_{1}^{\prime}$, and $e_{l}$ denotes the vector of dimension $2 n$ with zero components except the component of order $l$ which is equal to 1 . We deduce the invariance property by a change of currency.

Proposition 1 : The foreign denominated securities have a dynamics similar to the corresponding domestic denominated securities. Their dynamic specifications are written with modified parameters to account for the exchange rate risk.

\subsection{The arbitrage-free restriction}

This section analyzes the restrictions that need to be imposed upon the previous stochastic processes to get an arbitrage free international economy. Since the sdf can be used to price all assets of interest, it is in particular valid for the $n$ market portfolios ${ }^{14}$ expressed in currency 1. This implies the no-arbitrage restrictions:

$$
E_{t}\left[M_{1, t, t+1} \exp y_{j \mid 1, t+1}\right]=1, \quad j=1, \ldots, n,
$$

where $E_{t}$ denotes the expectation conditional on the information available at $t$, that is $\underline{\Sigma_{t}}, \underline{\varepsilon_{1 \mid t}}$. The arbitrage-free restrictions are equivalent to:

$$
\begin{aligned}
& E_{t}\left[\operatorname { e x p } \left\{c_{1}+\operatorname{Tr}\left(C_{1}^{0} \Sigma_{t}\right)+\operatorname{Tr}\left(C_{1} \Sigma_{t+1}\right)+\gamma_{1}^{\prime} \varepsilon_{\mid 1, t+1}+f_{j \mid 1}+\operatorname{Tr}\left(F_{j \mid 1}^{0} \Sigma_{t}\right)\right.\right. \\
& \left.\left.+\operatorname{Tr}\left(F_{j \mid 1} \Sigma_{t+1}\right)+\varepsilon_{j+n \mid 1, t+1}\right\}\right]=1, j=1, \ldots, n .
\end{aligned}
$$

Applying the iterated expectation theorem, we can integrate out the innovation $\varepsilon_{\mid 1, t+1}$ conditional on $\Sigma_{t+1}$. Let us denote $e_{j+n}$ the 2 n-dimensional vector with zero components

14 We implicitly assume that the market portfolio is tradable. 
except the $(j+n)^{t h}$ component, equal to one. We get:

$$
\begin{aligned}
& E_{t}\left[\operatorname { e x p } \left\{c_{1}+f_{j \mid 1}+\operatorname{Tr}\left[\left(C_{1}^{0}+F_{j \mid 1}^{0}\right) \Sigma_{t}\right]+\operatorname{Tr}\left[\left(C_{1}+F_{j \mid 1}\right) \Sigma_{t+1}\right]\right.\right. \\
& \left.\left.+\frac{1}{2}\left(\gamma_{1}+e_{j+n}\right)^{\prime} A_{1}^{\prime} \Sigma_{t+1} A_{1}\left(\gamma_{1}+e_{j+n}\right)\right\}\right] \\
= & \exp \left[c_{1}+f_{j \mid 1}+\operatorname{Tr}\left[\left(C_{1}^{0}+F_{j \mid 1}^{0}\right) \Sigma_{t}\right]\right] \\
& E_{t} \exp \operatorname{Tr}\left(\left[C_{1}+F_{j \mid 1}+\frac{1}{2} A_{1}\left(\gamma_{1}+e_{j+n}\right)\left(\gamma_{1}+e_{j+n}\right)^{\prime} A_{1}^{\prime}\right] \Sigma_{t+1}\right) \\
= & \exp \left[c_{1}+f_{j \mid 1}+\operatorname{Tr}\left(\left(C_{1}^{0}+F_{j \mid 1}^{0}\right) \Sigma_{t}\right)\right] \\
& \left\{\exp \operatorname{Tr}\left[M^{\prime} \Gamma_{j \mid 1}\left(I d-2 \Omega \Gamma_{j \mid 1}\right)^{-1} M \Sigma_{t}\right]\right\}\left[\operatorname{det}\left(I d-2 \Omega \Gamma_{j \mid 1}\right)\right]^{-K / 2},
\end{aligned}
$$

where:

$$
\Gamma_{j \mid 1}=C_{1}+F_{j \mid 1}+\frac{1}{2} A_{1}\left(\gamma_{1}+e_{j+n}\right)\left(\gamma_{1}+e_{j+n}\right)^{\prime} A_{1}^{\prime} .
$$

The arbitrage-free restrictions are immediately deduced.

Proposition 2 : The joint choice of the domestic sdf and asset dynamics is restricted by the arbitrage-free conditions:

$$
\begin{aligned}
c_{1}+f_{j \mid 1}-\frac{K}{2} \log \operatorname{det}\left(I d-2 \Omega \Gamma_{j \mid 1}\right) & =0, \forall j, \\
C_{1}^{0}+F_{j \mid 1}^{0}+M^{\prime} \Gamma_{j \mid 1}\left(I d-2 \Omega \Gamma_{j \mid 1}\right)^{-1} M & =0, \forall j,
\end{aligned}
$$

where the matrix $\Gamma_{j \mid 1}$ is given by equation $(2.2)$.

The arbitrage-free restrictions are fixing some drift components for all quanto market indexes. We get:

$$
\begin{aligned}
y_{j \mid 1, t+1} & =-c_{1}+\frac{K}{2} \log \operatorname{det}\left[\operatorname{Id}-2 \Omega \Gamma_{j \mid 1}\right] \\
& +\operatorname{Tr}\left\{\left[-C_{1}^{0}-M^{\prime} \Gamma_{j \mid 1}\left(I d-2 \Omega \Gamma_{j \mid 1}\right)^{-1} M\right] \Sigma_{t}\right\} \\
& +\operatorname{Tr}\left(F_{j \mid 1} \Sigma_{t+1}\right)+\varepsilon_{j+n \mid 1, t+1}
\end{aligned}
$$

It is not surprising to get a restriction between the predetermined components of the sdf and expected market returns. For instance the limiting case $M=0, \Omega=0$, corresponds to zero risk : $\Sigma_{t}=0$, we have no uncertainty and all returns coincide in the riskfree world. 
Indeed $y_{j \mid 1, t+1}=-c_{1}$ is independent of $j$ and coincides with the common return of all Arrow-Debreu securities.

Remark 1 : Since the fundamental risk factor $\Sigma_{t}$ is exogenous, the observability of the domestic and foreign interest rates does not imply additional arbitrage-free restrictions. For instance from: $M_{l, t, t+1}=M_{1, t, t+1} \exp r_{l \mid 1, t+1}$, and applying the conditional expectation to both sides of the equation, we get:

$$
E_{t} M_{l, t, t+1}=\exp -r_{l}(t+1)=E_{t}\left(M_{1, t, t+1} \exp r_{l \mid 1, t+1}\right)
$$

The pricing operator applied to currencies simply defines the new variables $r_{l}(t+1)$ corresponding to the short term interest rate in country $l$; the complete term structures will be derived in Section 3.

Remark 2 : The specification introduced in Section 2.1 and the arbitrage-free restrictions are easily extended to the pricing of stocks with payment of dividends, or to commodities with convenience yield including (minus) the cost of carry. Let us for instance consider stocks with dividends. We have just to introduce a second discount factor $M_{1, t, t+1}^{*}$, say, representing the discounting associated with dividends, to assume an exponential affine expression for $M_{1, t, t+1}^{*}$ too, and to change the arbitrage-free condition into $E_{t}\left[M_{1, t, t+1} M_{1, t, t+1}^{*} \exp y_{j \mid 1, t+1}\right]=1, j=1, \ldots, n$, where the $y_{j \mid 1, t+1}$ are the ex-dividend returns. Note that all dividends are also expressed in domestic currency. Thus the dividends associated with a foreign market portfolio are transformed into "quanto-dividends".

Remark 3 : The assumption of conditionally Gaussian error terms can be weakened. The above results are still valid if:

$$
E_{t}\left[\exp \left(\gamma^{\prime} \varepsilon_{\mid 1, t+1}\right) \mid \Sigma_{t+1}\right]
$$

can be written as : $\exp \left[a(\gamma)+\operatorname{Tr}\left(B(\gamma) A_{1}^{\prime} \Sigma_{t+1} A_{1}\right)\right]$, say. Thus the model is compatible with an error term admitting a conditional tail larger than Gaussian. 


\subsection{Risk neutral probabilities}

In currency $l$, the conditional density of the risk neutral probability with respect to the historical probability is given by:

$$
q_{l, t, t+1}=M_{l, t, t+1} \exp r_{l}(t, 1)=M_{l, t, t+1} / E_{t}\left[M_{l, t, t+1}\right], l=1, \ldots, n .
$$

This density is an exponential affine function of $\Sigma_{t}$ and $\Sigma_{t+1}$, which can be expressed in terms of the domestic risk neutral density $q_{1, t, t+1}$. We get:

$$
\begin{aligned}
q_{l, t, t+1} & =M_{1, t, t+1} \exp r_{l \mid 1, t+1} / E_{t}\left[M_{1, t, t+1} \exp r_{l \mid 1, t+1}\right] \\
& =q_{1, t, t+1} \exp r_{l \mid 1, t+1} E_{t}\left(M_{1, t, t+1}\right) / E_{t}\left[M_{1, t, t+1} \exp r_{l \mid 1, t+1}\right] \\
& =q_{1, t, t+1} \frac{\exp r_{l \mid 1, t+1}}{E_{t}^{* 1}\left(\exp r_{l \mid 1, t+1}\right)},
\end{aligned}
$$

where $E_{t}^{* 1}$ denotes the expectation with respect to the domestic risk neutral probability.

\section{Domestic and foreign term structures}

The coherent modelling defined by assumptions A1-A4 is appropriate for analyzing the link between domestic and foreign term structures, and especially for examining how this link depends on the dynamics of exchange rates. All these relations depend on the way the common risk factor affects the exchange rates and the domestic sdf. We provide numerical examples with realistic parameter values to illustrate these relations.

\subsection{Closed-form expressions of the term structures}

Let us first consider the domestic bond market and denote by $B_{1}(t, h)$ the price at $t$ of a zero-coupon bond with residual maturity $h$. The recursive bond pricing formula:

$$
B_{1}(t, h)=E_{t}\left[M_{1, t, t+1} B_{1}(t+1, h-1)\right],
$$

and the expression of the domestic sdf (see Assumption A.3):

$$
M_{1, t, t+1}=\exp \left[c_{1}+\operatorname{Tr}\left(C_{1}^{0} \Sigma_{t}\right)+\operatorname{Tr}\left(C_{1} \Sigma_{t+1}\right)+\gamma_{1}^{\prime} \varepsilon_{\mid 1, t+1}\right],
$$


allows us to derive the affine term structure along the lines of Gourieroux, Monfort, Polimenis (2002) (see Appendix 1).

Proposition 3 : We have:

$$
B_{1}(t, h)=\exp \left\{\operatorname{Tr}\left[\Phi_{1}(h) \Sigma_{t}\right]+\varphi_{1}(h)\right\}, \quad \text { for } h \geq 0
$$

where the matrix $\Phi_{1}(h)$ and the scalar $\varphi_{1}(h)$ satisfy the recursive equations:

$$
\begin{aligned}
\Phi_{1}(h)= & C_{1}^{0}+M^{\prime}\left[C_{1}+\Phi_{1}(h-1)+\frac{1}{2} A_{1} \gamma_{1} \gamma_{1}^{\prime} A_{1}^{\prime}\right] \\
& {\left[I d-2 \Omega\left[C_{1}+\Phi_{1}(h-1)+\frac{1}{2} A_{1} \gamma_{1} \gamma_{1}^{\prime} A_{1}^{\prime}\right]\right]^{-1} M, } \\
\varphi_{1}(h)= & c_{1}+\varphi_{1}(h-1)-\frac{K}{2} \log \operatorname{det}\left\{I d-2 \Omega\left[C_{1}+\Phi_{1}(h-1)+\frac{1}{2} A_{1} \gamma_{1} \gamma_{1}^{\prime} A_{1}^{\prime}\right]\right\},
\end{aligned}
$$

for $h \geq 0$, with initial conditions $\Phi_{1}(0)=0, \varphi_{1}(0)=0$ corresponding to $B_{1}(t, 0)=1$.

In particular the geometric yields : $r_{1}(t, h)=-\frac{1}{h} \log B_{1}(t, h)$, are affine functions of the risk factors, represented by the fundamental volatilities and covolatilities, which are the elements of $\Sigma_{t}$. We get a domestic affine term structure, called Wishart quadratic term structure in the literature (Gourieroux, Sufana (2003)).

The specification is convenient for discussing the nonnegativity of interest rates $r_{1}(t, h)$ at all maturities. First note that these rates are nonnegative whenever the short term interest rate $r_{1}(t, 1)$ is nonnegative. Since:

$$
r_{1}(t, 1)=-\operatorname{Tr}\left[\Phi_{1}(1) \Sigma_{t}\right]-\varphi_{1}(1)
$$

the nonnegativity condition is satisfied for any admissible risk factor $\Sigma_{t}$, if and only if $\varphi_{1}(1) \leq 0$ and $-\Phi_{1}(1)$ is positive semidefinite. This implies joint restrictions on parameters $C_{1}^{0}, C_{1}, M, \Omega, A_{1}, \gamma_{1}, c_{1}$. When these restrictions are satisfied: $B_{1}(t, 1)=E_{t} M_{1, t, t+1}$ is smaller than 1, but the domestic sdf itself is still stochastic, with values smaller or larger than 1.

The results of Proposition 3 are easily transposed to the foreign term structures by 
using the invariance by change of currency (see Section 2.2).

Corollary 1 : The term structures of the different countries are jointly affine.

However these term structures may have different features in terms of time series or cross-sectional properties. In the two next sections we consider numerical examples, discuss the joint dynamics of the exchange rate and interest rates (Section 3.2) and the associated term structure patterns (Section 3.3).

The (domestic) term structure of short term forward rates, which is the basis of HeathJarrow-Morton approach, is easily derived from Proposition 3. Indeed we have:

$$
f_{1, t, T}=-\log \frac{B_{1}(t, t-T)}{B_{1}(t, t-T-1)},
$$

and therefore:

$$
\begin{aligned}
f_{1, t, T}-f_{1,0, T}= & \operatorname{Tr}\left[\left[\Phi_{1}(T-t-1)-\Phi_{1}(T-t)\right] \Sigma_{t}\right]+\varphi_{1}(T-t-1)-\varphi_{1}(T-t) \\
& -\operatorname{Tr}\left[\left[\Phi_{1}(T-1)-\Phi_{1}(T)\right] \Sigma_{0}\right]-\varphi_{1}(T-1)+\varphi_{1}(T) .
\end{aligned}
$$

This forward term structure is driven linearly by the Wishart factor $\Sigma_{t}$.

\subsection{Interactions between domestic and foreign short term interest rates}

We consider the case of two countries $(n=2)$, three factors represented by two volatilities and one covolatility $(L=2)$, and a degree of freedom $K=2$; we also assume that there are no specific risks $\left(A_{1}=0\right)$, no lagged effect $\left(C_{1}^{0}=D_{2 \mid 1}^{0}=0\right)$, take a diagonal matrix $M$ and an identity matrix $\Omega$; in other words, the risk factor can be decomposed as: $\Sigma_{t}=x_{1 t} x_{1 t}^{\prime}+x_{2 t} x_{2 t}^{\prime}$, where $\left(x_{i t}\right), i=1,2$, are independent bivariate processes, whose

components $\left(x_{i t}^{(1)}\right),\left(x_{i t}^{(2)}\right)$ are themselves Gaussian, independent and autoregressive of order 1:

$$
x_{i t}^{(1)}=m_{1} x_{i, t-1}^{(1)}+\varepsilon_{i t}^{(1)},
$$




$$
x_{i t}^{(2)}=m_{2} x_{i, t-1}^{(2)}+\varepsilon_{i t}^{(2)}, \quad i=1,2,
$$

where $m_{1}, m_{2}$ are the diagonal terms of $M$ and the $\varepsilon_{i t}^{(j)}, j=1,2$, are $\operatorname{IIN}(0,1)$ [see Gourieroux, Jasiak, Sufana (2003)]. In particular, denoting the entries of $\Sigma_{t}$ by $\sigma_{1 t}^{2}, \sigma_{2 t}^{2}$, $\sigma_{12 t}$, we have:

$$
\begin{aligned}
\sigma_{1 t}^{2} & =\left(x_{1 t}^{(1)}\right)^{2}+\left(x_{2 t}^{(1)}\right)^{2}, \\
\sigma_{2 t}^{2} & =\left(x_{1 t}^{(2)}\right)^{2}+\left(x_{2 t}^{(2)}\right)^{2}, \\
\sigma_{12 t} & =x_{1 t}^{(1)} x_{1 t}^{(2)}+x_{2 t}^{(1)} x_{2 t}^{(2)} .
\end{aligned}
$$

Finally we assume that the domestic sdf $M_{1, t, t+1}$ only depends on $\sigma_{1, t+1}^{2}$, that is: $C_{1}=\lambda_{1}\left[\begin{array}{ll}1 & 0 \\ 0 & 0\end{array}\right]$, and that the exchange rate $r_{2 \mid 1, t+1}$ only depends on $\sigma_{2, t+1}^{2}$, that is: $D_{2 \mid 1}=\lambda_{2}\left[\begin{array}{ll}0 & 0 \\ 0 & 1\end{array}\right]$. In particular the domestic sdf and the exchange rate follow independent dynamics.

Then three dynamic models M1, M2, M3 are considered.

M1: In this model, we take: $m_{1}=m_{2}=0.1$, that is weakly autocorrelated basic factors $x_{i t}^{(1)}$ and $x_{i t}^{(2)}$. We also take: $c_{1}=-0.05, \lambda_{1}=-10^{-2}, d_{2 \mid 1}=0, \lambda_{2}=-10^{-3}$. The historical (i.e. unconditional) densities of the domestic and foreign short term interest rates are displayed in Figure 1. They correspond to noncentral chi-square distributions, since the Wishart based models are direct extensions of the Cox-Ingersoll-Ross model. Moreover the two series of short term rates are weakly autocorrelated (see the autocorrelograms displayed in Figure 2).

[Insert Figure 1: Unconditional density function of $r_{1}$ and $r_{2}$ ]

[Insert Figure 2: Autocorrelogram of $r_{2 \mid 1}, r_{1}$ and $r_{2}$ ]

M2: In this model, we take: $m_{1}=0.1$ and $m_{2}=0.9$. Thus the basic factors $x_{i t}^{(1)}$ are weakly autocorrelated, whereas the basic factors $x_{i t}^{(2)}$ will feature high persistence. We also take: $c_{1}=-0.05, \lambda_{1}=-10^{-2}, d_{2 \mid 1}=0, \lambda_{2}=-10^{-4}$. In this example, $r_{1}(t)$ 
is weakly autocorrelated since the domestic sdf only depends on $\sigma_{1, t+1}^{2} ; r_{2 \mid 1, t}$ is highly autocorrelated, since it depends on $\sigma_{2, t+1}^{2}$, and $r_{2}(t)$ is also highly autocorrelated because of the impact of the exchange rate dynamics on the dynamics of the foreign sdf (see Figure 4). The historical densities of the short term interest rates are displayed in Figure 3. We observe the large increase of the tail magnitude of the foreign interest rate, which is a consequence of the high persistence of the exchange rate. ${ }^{15}$

[Insert Figure 3: Unconditional density function of $r_{1}$ and $r_{2}$ ]

[Insert Figure 4: Autocorrelogram of $r_{2 \mid 1}, r_{1}$ and $r_{2}$ ]

M3: In this model, we take: $m_{1}=0.9$ and $m_{2}=0.1$. Thus the basic factors $x_{i t}^{(1)}$ are highly autocorrelated whereas the basic factors $x_{i t}^{(2)}$ are weakly autocorrelated. We also take: $c_{1}=-0.05, \lambda_{1}=-10^{-4}, d_{2 \mid 1}=0.02, \lambda_{2}=-10^{-2}$. In this case, both $r_{1}(t)$ and $r_{2}(t)$ are strongly autocorrelated because the domestic sdf is strongly autocorrelated and, although the relative change of the exchange rate is weakly autocorrelated, the foreign sdf is also highly autocorrelated (see Figure 6). Both unconditional densities feature rather fat tails (see Figure 5).

[Insert Figure 5: Unconditional density function of $r_{1}$ and $r_{2}$ ]

[Insert Figure 6: Autocorrelogram of $r_{2 \mid 1}, r_{1}$ and $r_{2}$ ]

\subsection{Term structure patterns}

Let us now discuss the effect of the joint dynamics of $r_{1}, r_{2 \mid 1}$ on the pricing formula. More precisely the aim of this section is to illustrate the flexibility of affine specifications and in

15 Detailed discussions on the link between the serial persistence and the tails of the unconditional density have been done in Gourieroux, Jasiak (2001), Gourieroux, Robert (2005). 
particular to show that a very large set of patterns can be obtained for both the domestic and foreign term structures of interest rates.

The domestic term structure of interest rates $r_{1}(t, h)=-\frac{1}{h} \log B_{1}(t, h)$ is given by Proposition 3. Assuming that $L=2$, that is a 3-factor model, and $K=2$, this term structure depends on the scalar $c_{1}$, on the $(2 \times 2)$ matrix $M$ (with eigenvalues smaller than 1 in modulus), on the $(2 \times 2)$ symmetric positive semi-definite matrix $\Omega$, on the $(2 \times 2)$ symmetric negative semidefinite matrices $C_{1}^{0}, C_{1}$ and on the $(2 \times 1)$ vector $A_{1} \gamma_{1}$.

Let us consider one foreign country; the term structure of interest rates in this country is given by $r_{2}(t, h)=-\frac{1}{h} \log B_{2}(t, h)$, where $B_{2}(t, h)$ is obtained from Proposition 2 in which $c_{1}$ is replaced by $c_{1}+d_{2 \mid 1}, C_{1}^{0}$ is replaced by $C_{1}^{0}+D_{2 \mid 1}^{0} \ll 0, C_{1}$ is replaced by $C_{1}+D_{2 \mid 1} \ll 0$, and $A_{1} \gamma_{1}$ is replaced by $A_{2} \gamma_{1}\left(\right.$ since $\left.\gamma_{2}=\gamma_{1}\right)$. Note that :

$$
A_{2} \gamma_{1}=A_{1}\left(I d-e_{2} e^{\prime}\right) \gamma_{1}=A_{1} \gamma_{1}+A_{1} e_{2}
$$

In summary, for $L$ and $K$ fixed to 2 , the parameters are $M, \Omega, c_{1}, C_{1}^{0}, C_{1}, A_{1} \gamma_{1}, d_{2 \mid 1}$, $D_{2 \mid 1}^{0}, D_{2 \mid 1}, A_{2} \gamma_{2}, \Sigma_{t}$. This large set of parameters allow for various shapes of the domestic and foreign term structures.

The choice of a three factor model is the minimal one to ensure deterministically independent evolutions of the level, slope and curvature of each term structure. But both domestic and foreign term structures depend on the same factors, which are the elements of the fundamental volatility matrix $\Sigma_{t}$. For instance one given factor can impact the slope of the domestic term structure and simultaneously the curvature of the foreign term structure. We consider below four dynamic models. The values of the parameters corresponding to these four cases and the current state of the environment are given in Appendix 3. Experiment I (see Figure 7) provides an example where both term structures are decreasing. In experiment II (see Figure 8) both term structures are increasing. In experiment III (see Figure 9) one curve is decreasing and the other one is increasing. Finally experiment IV (see Figure 10) provides an example where one curve 
is not monotonic.

[Insert Figure 7 : Term Structure of Interest Rates, Experiment I]

[Insert Figure 8 : Term Structure of Interest Rates, Experiment II]

[Insert Figure 9 : Term Structure of Interest Rates, Experiment III]

[Insert Figure 10 : Term Structure of Interest Rates, Experiment IV]

\section{Pricing futures and forward contracts}

In this section we derive closed form pricing formulas for standard forward and futures contracts. These formulas are based on a lemma providing the multihorizon conditional Laplace transform of the fundamental risk.

\subsection{Multihorizon prediction}

Lemma 1 : Suppose that $\left(\Sigma_{t}\right)$ is a WAR process defined in Assumption A.4 and let us consider the conditional multihorizon Laplace transform:

$$
E\left\{\exp \operatorname{Tr}\left(\wedge_{t+1} \Sigma_{t+1}+\wedge_{t+2} \Sigma_{t+2}+\ldots+\wedge_{T} \Sigma_{T}\right) \mid \Sigma_{t}\right\}
$$

This conditional Laplace transform is given by:

$$
\exp \left[\operatorname{Tr}\left(\Phi^{[\wedge]}(t, T) \Sigma_{t}\right)+\varphi^{[\wedge]}(t, T)\right]
$$

where the operators $\Phi^{[\wedge]}(t, T)$ and $\varphi^{[\wedge]}(t, T)$ are defined by the backward recursion:

$$
\Phi^{[\wedge]}(t, T)=M^{\prime}\left[\wedge_{t+1}+\Phi^{[\wedge]}(t+1, T)\right]\left[I d-2 \Omega\left(\wedge_{t+1}+\Phi^{[\wedge]}(t+1, T)\right)\right]^{-1} M,
$$

and

$$
\varphi^{[\wedge]}(t, T)=-\frac{K}{2} \log \operatorname{det}\left[I d-2 \Omega\left(\wedge_{t+1}+\Phi^{[\wedge]}(t+1, T)\right)\right]+\varphi^{[\wedge]}(t+1, T),
$$

for $h>0$, with terminal conditions:

$$
\Phi^{[\wedge]}(T, T)=0, \quad \varphi^{[\wedge]}(T, T)=0, \quad \forall T .
$$


Proof : See Appendix 2.

\subsection{Pricing futures contracts}

\subsubsection{Futures on foreign market indexes}

Let us denote by $S_{j \mid 1, t}$ the domestic denominated index of market $j$ at time $t$. We have:

$$
S_{j \mid 1, t}=S_{j \mid 1, t-1} \exp y_{j \mid 1, t}
$$

The domestic futures price of the market $j$ index for maturity $T$ is given by:

$$
S_{j \mid 1}^{F}(t, T)=E_{t}^{Q_{1}} S_{j \mid 1, T}
$$

where $Q_{1}$ is the domestic risk neutral probability defined in Section 2.4.

Therefore we have:

$$
S_{j \mid 1}^{F}(t, T)=S_{j \mid 1, t} E_{t}\left[\frac{M_{1, t, t+1} \ldots M_{1, T-1, T}}{E_{t} M_{1, t, t+1} \ldots E_{T-1} M_{1, T-1, T}} \exp \left(y_{j \mid 1, t+1}+\ldots+y_{j \mid 1, T}\right)\right] .
$$

Proposition 4 : The futures price $S_{j \mid 1}^{F}(t, T)$ is given by:

$$
\begin{aligned}
S_{j \mid 1}^{F}(t, T)= & S_{j \mid 1, t} \exp \left\{(T-t) \tilde{f}_{j \mid 1}+\frac{(T-t) K}{2} \log \operatorname{det}\left[I d-2 \Omega\left(C_{1}+\frac{1}{2} \gamma_{1} \gamma_{1}^{\prime} A_{1}^{\prime} A_{1}\right)\right]+\varphi^{[\wedge]}(t, T)\right. \\
& \left.+\operatorname{Tr}\left[\left(\wedge_{0}+\Phi^{[\wedge]}(t, T)\right) \Sigma_{t}\right]\right\}
\end{aligned}
$$

where $\Phi^{[\wedge]}(t, T), \varphi^{[\wedge]}(t, T)$ are obtained recursively using the formulae of Lemma 1 for the sequence of matrices $\left(\wedge_{1}, \ldots, \wedge_{1}, \wedge_{2}\right)$, where:

$$
\begin{aligned}
& \wedge_{0}=G_{1}^{0}+\tilde{F}_{j \mid 1}^{0}, \\
& \wedge_{1}=C_{1}+F_{j \mid 1}+G_{1}^{0}+\tilde{F}_{j \mid 1}^{0}+\frac{1}{2} A_{1}\left(\gamma_{1}+e_{j+n}\right)\left(\gamma_{1}+e_{j+n}\right)^{\prime} A_{1}^{\prime}, \\
& \wedge_{2}=C_{1}+F_{j \mid 1}+\frac{1}{2} A_{1}\left(\gamma_{1}+e_{j+n}\right)\left(\gamma_{1}+e_{j+n}\right)^{\prime} A_{1}^{\prime},
\end{aligned}
$$


with:

$$
\begin{aligned}
\tilde{f}_{j \mid 1} & =-c_{1}+\frac{K}{2} \log \operatorname{det}\left(I d-2 \Omega \Gamma_{j \mid 1}\right), \quad \tilde{F}_{j \mid 1}^{0}=-C_{1}^{0}-M^{\prime} \Gamma_{j \mid 1}\left(I d-2 \Omega \Gamma_{j \mid 1}\right)^{-1} M, \\
G_{1}^{0} & =-M^{\prime} \Gamma_{3}\left(I d-2 \Omega \Gamma_{3}\right)^{-1} M, \quad \Gamma_{3}=C_{1}+\frac{1}{2} \gamma_{1} \gamma_{1}^{\prime} A_{1}^{\prime} A_{1} .
\end{aligned}
$$

Proof : See Appendix 4.

\subsubsection{Futures on exchange rates}

Let us denote by $R_{j \mid 1, t}$ the exchange rate of currency $j$ at time $t$, denominated in domestic currency. We have:

$$
R_{j \mid 1, t}=R_{j \mid 1, t-1} \exp r_{j \mid 1, t} .
$$

Therefore we can easily find the price of a futures written on the exchange rate with maturity $T$ just replacing $y_{j \mid 1, t}$ by $r_{j \mid 1, t}$ in the above subsection.

\subsection{Pricing forward contracts}

\subsubsection{Forwards on foreign market indexes}

Two cases have to be distinguished. In case a) the delivery price $K$ is specified in domestic currency. In case b) the delivery price $K$ is specified in foreign currency and the payoff at the settlement date $T$ is the difference between the prevailing price of the index (in foreign currency) and this delivery price converted in domestic currency at a predetermined exchange rate $\underline{R}$. This latter type of contract is called a quanto-forward contract. So the domestic payoffs at $T$ are, respectively:

$$
\begin{array}{ll}
\text { case a): } & S_{j \mid 1, T}-K ; \\
\text { case b): } & \underline{R}\left(S_{j \mid j, T}-K\right) .
\end{array}
$$

In both cases the delivery price $K$ is fixed to get a zero value of the contract at the 
agreement date $t$. This implies:

$$
\text { case a): } \quad K_{a}=S_{j \mid 1}^{f}(t, T)=\frac{S_{j \mid 1, t}}{B_{1}^{*}(t, T)},
$$

where $B_{1}^{*}(t, T)=B_{1}(t, T-t)$, and:

$$
\text { case b): } \quad \underline{R} K_{b}=S_{j \mid 1}^{q}(t, T)=\frac{\underline{R} S_{j \mid j, t}}{B_{j}^{*}(t, T)}=\frac{\underline{R} S_{j \mid 1, t}}{R_{j \mid 1, t} B_{j}^{*}(t, T)} .
$$

In particular, if $\underline{R}=R_{j \mid 1, t}$, we get:

$$
S_{j \mid 1}^{q}(t, T)=\frac{S_{j \mid 1, t}}{B_{j}^{*}(t, T)} .
$$

In case a) the domestic term structure is involved, whereas in case b) the foreign term structure is involved. In both cases the prices are explicit since the domestic and foreign term structures are explicit as seen in Section 3.

\subsubsection{Forwards on exchange rates}

In a forward contract on exchange rate with settlement date $T$ and price $K$ (denominated in domestic currency), the payoff at $T$ is $R_{j \mid 1, T}-K$. The delivery price $K$ is fixed to get a zero value of the forward contract at the agreement date $t$. The value at date $t$ of $R_{j \mid 1, T}$, in currency $j$, is the value at date $t$ of one unit of currency $j$ delivered at date $T$, namely $B_{j}^{*}(t, T)$, and the domestic price is $R_{j \mid 1, t} B_{j}^{*}(t, T)$. Therefore the forward price for a forward exchange rate is:

$$
R_{j \mid 1, t}^{f}=\frac{R_{j \mid 1, t} B_{j}^{*}(t, T)}{B_{1}^{*}(t, T)} .
$$

Again an explicit formula is derived from the formulae of both term structures.

\section{Pricing swaps and options}

In our international framework it is also possible to derive closed form formulae for pricing swaps and quasi-explicit formulae for pricing many options, that is which require only the computation of a univariate integral. 


\subsection{A preliminary lemma}

Let us consider a vector $Z_{t, T}$ whose entries are made from any subset of the $y_{j \mid 1, \tau}(j=$ $1, \ldots, n ; \tau=t+1, \ldots, T), r_{j \mid 1, \tau}(j=2, \ldots, n ; \tau=t+1, \ldots, T)$, and vech $\Sigma_{t}(\tau=t+1, \ldots, T)^{16}$.

Lemma 2 : For any vector $w$ with real components, the price at date $t$ of $\exp \left(w^{\prime} Z_{t, T}\right)$ (in domestic currency) is exponential affine in $\Sigma_{t}$ and is recursively computable.

Proof : The price is:

$$
E_{t}\left[M_{1, t, t+1} \ldots M_{1, T-1, T} \exp \left(w^{\prime} Z_{t, T}\right)\right]
$$

Replacing the stochastic discount factors and the components of $Z_{t, T}$ in terms of the $\Sigma_{\tau}$ and $\varepsilon_{\mid 1, \tau}(\tau=t+1, \ldots, T)$ using their expressions given in Section 2.1, we get:

$$
E_{t} \exp \left[v_{0}+\sum_{\tau=t}^{T} \operatorname{Tr}\left(V_{\tau} \Sigma_{\tau}\right)+\sum_{\tau=t+1}^{T} v_{\tau}^{\prime} \varepsilon_{\mid 1, \tau}\right]
$$

where $v_{0}, V_{\tau}, v_{\tau}$, are functions of $w$. Integrating with respect to $\varepsilon_{\mid 1, \tau}$ we get:

$$
\exp \left[v_{0}+V_{t} \Sigma_{t}\right] E_{t} \exp \left[\sum_{\tau=t}^{T} \operatorname{Tr}\left(V_{\tau}+A_{1} v_{\tau} v_{\tau}^{\prime} A_{1}\right) \Sigma_{\tau}\right]
$$

and the result follows from Lemma 1.

\subsection{Pricing cross-currency swaps}

Let us first recall that the linear (or arithmetic, or simply compounded, or LIBOR) interest rate at time $t$ for maturity $T$ and currency $j$ is:

$$
L_{j}(t, T)=\frac{1-B_{j}^{*}(t, T)}{(T-t) B_{j}^{*}(t, T)} .
$$

A general floating-for-floating cross-currency swap has a sequence of payoffs at dates $T_{s}$, $s=1, \ldots, S,\left(\right.$ with $\left.T_{s+1}>T_{s}\right)$ of the form:

$$
\left[L_{k}\left(T_{s-1}, T_{s}\right)-L_{l}\left(T_{s-1}, T_{s}\right)\right] R_{m \mid 1, T_{s}}
$$

16 vech $\Sigma$ denotes the vector whose components are the different elements of matrix $\Sigma$. 
Thus three currencies $k, l, m$, are involved and this is a swap between currencies $k$ and $l$ per unit of currency $m$. Such a payoff can be written:

$$
\frac{1}{T_{s}-T_{s-1}}\left[\frac{1}{B_{k}^{*}\left(T_{s-1}, T_{s}\right)}-\frac{1}{B_{l}^{*}\left(T_{s-1}, T_{s}\right)}\right] R_{m \mid 1, T_{s}} .
$$

Since the zero-coupon prices are exponential affine functions of $\Sigma_{T_{s}-1}$, such a payoff is the difference of expressions of the form considered in Lemma 2. Therefore such a swap can be explicitly priced at any date $t<T_{1}$.

\subsection{Option pricing}

For option pricing we will use the inversion formula of complex Laplace transform given in Duffie, Pan, Singleton (2000). From this result we know that the complex Laplace transform $E_{t}\left[M_{1, t, t+1} \ldots M_{1, T-1, T} \exp \left(w^{\prime} Z_{t, T}\right)\right]$, where $w$ has complex components computed as indicated in Lemma 2, can be used to deduce truncated real Laplace transforms of the form

$$
E_{t}\left[M_{1, t, t+1} \ldots M_{1, T-1, T} \exp \left(w_{0}^{\prime} Z_{t, T}\right)\right] \mathbf{1}_{\left(w_{1}^{\prime} Z_{t, T}<\lambda\right)},
$$

where $w_{0}$ and $w_{1}$ are real vectors and $\lambda$ is a scalar. It is worth noting that any derivative whose payoff at $T$ is of the form:

$$
\left[\exp \left(w_{30}+w_{3}^{\prime} Z_{t, T}\right)-\exp \left(w_{40}+w_{4}^{\prime} Z_{t, T}\right)\right]^{+},
$$

can be priced quasi-explicitly since this payoff can be written as:

$$
\exp \left(w_{30}\right) \exp \left(w_{3}^{\prime} Z_{t, T}\right)\left[1-\exp \left(w_{50}+w_{5}^{\prime} Z_{t, T}\right)\right]^{+},
$$

with $w_{50}=w_{40}-w_{30}, w_{5}=w-w_{3}$, or:

$$
\exp \left(w_{30}\right) \exp \left(w_{3}^{\prime} Z_{t, T}\right) \mathbf{1}_{\left(w_{5}^{\prime} Z_{t, T}<-w_{50}\right)}-\exp \left(w_{40}\right) \exp \left(w_{4}^{\prime} Z_{t, T}\right) \mathbf{1}_{\left(w_{5}^{\prime} Z_{t, T}<-w_{50}\right)},
$$

which is a difference of expressions of type (5.1).

Many payoffs can be written under the form (5.2). Examples are options on foreign indexes (struck in domestic or foreign currencies), quanto-options, equity-linked foreign 
exchange rate options (ELFX), options on futures contracts, options on forward contracts, options on zero-coupon bonds. Moreover, it is well-known that whenever options on zero-coupon bonds are explicitly priced, the same is true for caps and floors. As usual derivatives which are more difficult to price are the options on coupon bonds and the swaptions $^{17}$.

\section{Concluding remarks}

The affine approach in which the underlying fundamental risk is represented by a stochastic symmetric positive definite matrix following Wishart process provides a convenient framework for the joint analysis of bonds, stocks, and currencies. It leads to closed-form solutions for the term structures of interest rates, for the forward and futures prices and for a large set of derivatives. The approach features an invariance property with respect to the change of basic currency, which allows us to derive similar results for any country of reference. Moreover the illustration shows that the specification is very flexible and able to reproduce various patterns of the domestic and foreign term structures.

17 Except if the payoff formula is linearized at some stage, as proposed by Brace, Musiela (1997). 


\section{Appendix 1. Derivation of the affine term structure}

Let us assume that:

$$
B_{1}(t, h)=\exp \left\{\operatorname{Tr}\left[\Phi_{1}(h) \Sigma_{t}+\varphi_{1}(h)\right]\right\}
$$

The recursive bond pricing formula implies that:

$$
\begin{aligned}
& B_{1}(t, h) \\
= & E_{t}\left[M_{1, t, t+1} B_{1}(t+1, h-1)\right] \\
= & E_{t} \exp \left[c_{1}+\operatorname{Tr}\left(C_{1}^{0} \Sigma_{t}\right)+\operatorname{Tr}\left(C_{1} \Sigma_{t+1}\right)+\gamma_{1}^{\prime} \varepsilon_{\mid 1, t+1}+\operatorname{Tr}\left[\Phi_{1}(h-1) \Sigma_{t+1}\right]+\varphi_{1}(h-1)\right] \\
= & E_{t} \exp \left[c_{1}+\varphi_{1}(h-1)+\operatorname{Tr}\left(C_{1}^{0} \Sigma_{t}\right)+\operatorname{Tr}\left(\left[C_{1}+\Phi_{1}(h-1)\right] \Sigma_{t+1}\right)+\frac{1}{2} \gamma_{1}^{\prime} A_{1}^{\prime} \Sigma_{t+1} A_{1} \gamma_{1}\right],
\end{aligned}
$$

(by iterated expectation theorem)

$$
=E_{t} \exp \left[c_{1}+\varphi_{1}(h-1)+\operatorname{Tr}\left(C_{1}^{0} \Sigma_{t}\right)+\operatorname{Tr}\left(C_{1}+\Phi_{1}(h-1)+\frac{1}{2} A_{1} \gamma_{1} \gamma_{1}^{\prime} A_{1}^{\prime}\right] \Sigma_{t+1}\right),
$$

(by commuting within the trace operator).

By applying Assumption A.4 we get:

$$
\begin{aligned}
B_{1}(t, h)= & \exp \left\{c_{1}+\varphi_{1}(h-1)-\frac{K}{2} \log \operatorname{det}\left[\operatorname{Id}-2 \Omega \Gamma_{2}(h-1)\right]\right. \\
& \left.+\operatorname{Tr}\left[\left\{C_{1}^{0}+M^{\prime} \Gamma_{2}(h-1)\left[I d-2 \Omega \Gamma_{2}(h-1)\right]^{-1} M\right\} \Sigma_{t}\right]\right\}
\end{aligned}
$$

where:

$$
\Gamma_{2}(h-1)=C_{1}+\Phi_{1}(h-1)+\frac{1}{2} A_{1} \gamma_{1} \gamma_{1}^{\prime} A_{1}^{\prime}
$$

The result follows by identifying the coefficients. 


\section{Appendix 2. The multihorizon prediction of the risk}

We have:

$$
\begin{aligned}
& E\left\{\exp \operatorname{Tr}\left(\wedge_{t+1} \Sigma_{t+1}+\ldots+\wedge_{T} \Sigma_{T}\right) \mid \Sigma_{t}\right\} \\
= & E\left\{E\left[\exp \operatorname{Tr}\left(\wedge_{t+1} \Sigma_{t+1}+\ldots+\wedge_{T} \Sigma_{T}\right) \mid \Sigma_{t+1}\right] \mid \Sigma_{t}\right\} \\
= & E\left\{\exp \left[\operatorname{Tr}\left(\wedge_{t+1}+\Phi^{[\wedge]}(t+1, T)\right) \Sigma_{t+1}+\varphi^{[\wedge]}(t+1, T) \mid \Sigma_{t}\right]\right\} \\
= & \exp \left[\operatorname{Tr}\left[M^{\prime}\left(\wedge_{t+1}+\Phi^{[\wedge]}(t+1, T)\right)\left[I d-2 \Omega\left(\wedge_{t+1}+\Phi^{[\wedge]}(t+1, T)\right)\right]^{-1} M \Sigma_{t}\right]\right. \\
& \left.-\frac{K}{2} \log \operatorname{det}\left[I d-2 \Omega\left(\wedge_{t+1}+\Phi^{[\wedge]}(t+1, T)\right)\right]+\varphi^{[\wedge]}(t+1, T)\right\} .
\end{aligned}
$$

The formulae of the lemma follow by identification. Moreover we have:

$$
\Phi^{[\wedge]}(t, t+1)=M^{\prime} \wedge_{t+1}\left(I d-2 \Omega \wedge_{t+1}\right)^{-1} M, \quad \varphi^{[\wedge]}(t, t+1)=-\frac{K}{2} \log \operatorname{det}\left[I d-2 \Omega \wedge_{t+1}\right],
$$

and, therefore:

$$
\Phi^{[\wedge]}(t+1, t+1)=0, \quad \varphi^{[\wedge]}(t+1, t+1)=0, \quad \forall t .
$$




\section{Appendix 3. Experiments}

In all experiments we have :

$$
\begin{aligned}
& C_{1}^{0}=-10^{-2}\left[\begin{array}{cc}
1 & 0.5 \\
0.5 & 1
\end{array}\right], \quad C_{1}=-10^{-2}\left[\begin{array}{cc}
1 & -0.9 \\
-0.9 & 1
\end{array}\right], \\
& A_{1} \gamma_{1}=10^{-2}\left[\begin{array}{l}
2 \\
1
\end{array}\right], \quad d_{2 \mid 1}=-0.02, \\
& D_{2 \mid 1}^{0}=0.9 C_{1}^{0}, \quad D_{2 \mid 1}=-0,5 C_{1}, \quad A_{2} \gamma_{2}=10^{-2}\left[\begin{array}{r}
-1 \\
-1
\end{array}\right], \\
& K \quad=2 \\
& \left.M \quad=\left[\begin{array}{rr}
-1 & -1 \\
1 & 0.6
\end{array}\right] \quad \text { (eigenvalues: }-0.2 \pm 0.6 i \text { modulus } 0.63\right)
\end{aligned}
$$

Moreover, in experiment I we have :

$$
\Omega=\left[\begin{array}{cc}
1 & -0.9 \\
-0.9 & 1
\end{array}\right], \quad c_{1}=0.1, \quad \Sigma_{t}=\left[\begin{array}{cc}
3 & -1 \\
-1 & 0,5
\end{array}\right]
$$

in experiment II we have :

$$
\Omega=\left[\begin{array}{ll}
1 & 0 \\
0 & 1
\end{array}\right], \quad c_{1}=0.15, \quad \Sigma_{t}=\left[\begin{array}{cc}
2.5 & -1.25 \\
-1.25 & 2.5
\end{array}\right]
$$

in experiment III we have : 


$$
\Omega=\left[\begin{array}{cc}
1 & -0.9 \\
-0.9 & 1
\end{array}\right], \quad c_{1}=0.08, \quad \Sigma_{t}=\left[\begin{array}{cc}
1 & -0.5 \\
-0.5 & 1
\end{array}\right]
$$

in experiment IV we have :

$$
\Omega=\left[\begin{array}{ll}
1 & 0 \\
0 & 1
\end{array}\right], \quad c_{1}=0.2, \quad \Sigma_{t}=\left[\begin{array}{cc}
0.4 & 0.1 \\
0.1 & 3
\end{array}\right] .
$$




\section{Appendix 4. Derivation of the futures price}

We show that the futures price involves the multihorizon conditional Laplace transform of the future path $\Sigma_{t+1}, \ldots, \Sigma_{T}$. Then we use the general formula given in Lemma 1 .

For any date $s$, we have:

$$
\begin{aligned}
\frac{M_{1, s, s+1}}{E_{s} M_{1, s, s+1}} & =\frac{\exp \left[\operatorname{Tr}\left(C_{1} \Sigma_{s+1}\right)+\gamma_{1}^{\prime} \varepsilon_{\mid 1, s+1}\right]}{E_{s} \exp \left[\operatorname{Tr}\left(C_{1} \Sigma_{s+1}\right)+\gamma_{1}^{\prime} \varepsilon_{\mid 1, s+1}\right]} \\
& =\exp \left[\operatorname{Tr}\left(C_{1} \Sigma_{s+1}\right)+\operatorname{Tr}\left(G_{1}^{0} \Sigma_{s}\right)+\gamma_{1}^{\prime} \varepsilon_{\mid 1, s+1}\right]\left[\operatorname{det}\left(\operatorname{Id}-2 \Omega \Gamma_{3}\right)\right]^{K / 2},
\end{aligned}
$$

with:

$$
G_{1}^{0}=-M^{\prime} \Gamma_{3}\left(I d-2 \Omega \Gamma_{3}\right)^{-1} M, \quad \Gamma_{3}=C_{1}+\frac{1}{2} \gamma_{1} \gamma_{1}^{\prime} A_{1}^{\prime} A_{1}
$$

Moreover from (3.2) we have:

$$
y_{j \mid 1, t+1}=\tilde{f}_{j \mid 1}+\operatorname{Tr}\left(\tilde{F}_{j \mid 1}^{0} \Sigma_{t}\right)+\operatorname{Tr}\left(F_{j \mid 1} \Sigma_{t+1}\right)+\varepsilon_{j+n \mid 1, t+1} .
$$

Thus, we get:

$$
\begin{aligned}
S_{j \mid 1}^{F}(t, T)= & S_{j \mid 1, t} \exp \left\{(T-t) \tilde{f}_{j \mid 1}+\frac{(T-t) K}{2} \log \operatorname{det}\left(I d-2 \Omega \Gamma_{3}\right)+\operatorname{Tr}\left[\left(G_{1}^{0}+\tilde{F}_{j \mid 1}^{0}\right) \Sigma_{t}\right]\right\} \\
& \times E_{t} \exp \left\{\operatorname{Tr}\left[\left[C_{1}+F_{j \mid 1}+G_{1}^{0}+\tilde{F}_{j \mid 1}^{0}+\frac{1}{2} A_{1}\left(\gamma_{1}+e_{j+n}\right)\left(\gamma_{1}+e_{j+n}\right)^{\prime} A_{1}^{\prime}\right] \Sigma_{t+1}\right]\right. \\
& +\cdots \\
& +\operatorname{Tr}\left[\left[C_{1}+F_{j \mid 1}+G_{1}^{0}+\tilde{F}_{j \mid 1}^{0}+\frac{1}{2} A_{1}\left(\gamma_{1}+e_{j+n}\right)\left(\gamma_{1}+e_{j+n}\right)^{\prime} A_{1}^{\prime}\right] \Sigma_{T-1}\right] \\
& \left.+\operatorname{Tr}\left[\left[C_{1}+F_{j \mid 1}+\frac{1}{2} A_{1}\left(\gamma_{1}+e_{j+n}\right)\left(\gamma_{1}+e_{j+n}\right)^{\prime} A_{1}^{\prime}\right] \Sigma_{T}\right]\right\} .
\end{aligned}
$$

Or, with clear notations:

$$
\begin{aligned}
S_{j \mid 1}^{F}(t, T)= & S_{j \mid 1, t} \exp \left\{(T-t) \tilde{f}_{j \mid 1}+\frac{(T-t) K}{2} \log \operatorname{det}\left(I d-2 \Omega \Gamma_{3}\right)+\operatorname{Tr}\left[\wedge_{0} \Sigma_{t}\right]\right\} \\
& E_{t} \exp \operatorname{Tr}\left[\wedge_{1}\left(\Sigma_{t+1}+\ldots+\Sigma_{T-1}\right)+\wedge_{2} \Sigma_{T}\right] .
\end{aligned}
$$

We conclude by using Lemma 1 . 


\section{References}

[1] Amin, K., and J., Bodurtha (1995) : "Discrete Time Valuation of American Options with Stochastic Interest Rates", Review of Financial Studies, 8, 193-234.

[2] Amin, K., and R., Jarrow (1991) : "Pricing Foreign Currency Options under Stochastic Interest Rates", Journal of International Money and Finance, 10, 310-330.

[3] Amin, K., and R., Jarrow (1993) : "Pricing Options on Risky Assets in a Stochastic Interest Rate Economy", Mathematical Finance, 2, 217-238.

[4] Amin, K., Ng. V., and S., Pirrong (1995) : "Valuing Energy Derivatives", in Managing Energy Price Risk, London, England : Risk Publications and Enron Capital and Trade Resources, 57-70.

[5] Ball, C., and A., Roma (1994) : "Stochastic Volatility Option Pricing", Journal of Financial and Quantitative Analysis, 29, 589-607.

[6] Bekaert, G., and G., Wu (2000): "Asymmetric Volatility and Risk in Equity Markets", Review of Financial Studies, 13, 1-42.

[7] Brace, A., and M., Musiela (1997): "Swap Derivatives in a Gaussian HJM Framework", in Mathematics of Derivative Securities, M., Dempster and S., Pliska, eds., Cambridge University Press, 336-368.

[8] Carr, P., and R., Jarrow (1995) : "A Discrete Time Synthesis of Derivative Security Valuation Using a Term Structure of Futures Prices", in Finance, vol 9 of Handbooks in Operations Research and Management Science, North-Holland, Chapter 7, 225-249.

[9] Cheng, S. (1991) : "On the Feasability of Arbitrage Based Option Pricing when Stochastic Bond Price Processes are Involved", Journal of Economic Theory, 53, 185198.

[10] Cortazar, G., and E., Schwartz (1994) : "The Valuation of Commodity Contingent 
Claims", Journal of Derivatives, 1, 27-39.

[11] Cox, J., Ingersoll, J., and S., Ross (1981) : "The Relation between Forward Prices and Futures Prices", Journal of Financial Economics, 9, 321-346.

[12] Dai, Q., and K., Singleton (2003) : "Term Structure Dynamics in Theory and Reality", Review of Financial Studies, 16, 631-678.

[13] Darolles, S., Gourieroux, C., and J., Jasiak (2005): "Structural Laplace Transform and Compound Autoregressive Models", forthcoming in Journal of Time Series Analysis.

[14] Dijkstra, T., and Y., Yao (2002) : "Moment Generating Function Approach to Pricing Interest Rate and Foreign Exchange Rate Claims", Insurance : Mathematics and Economics, 31, 163-178.

[15] Duffie, D., and R., Kan (1996) : "A Yield Factor Model of Interest Rates", Mathematical Finance, 6, 379-406.

[16] Duffie, D., Pan, J., and K., Singleton (2000): "Transform Analysis and Asset Pricing for Affine Jump Diffusions," Econometrica, 68, 1343-1376.

[17] Ferson, W. (2003) : "Tests of Multifactor Pricing Models, Volatility Bounds and Portfolio Performance", in G., Constantinides, M., Harris and R., Stultz (editors): Handbook of the Economics of Finance, Elsevier Science Publishers, North Holland (forthcoming).

[18] Gibson, R., and E., Schwartz (1990) : "Stochastic Convenience Yield and the Pricing of Oil Contingent Claims", Journal of Finance, 45, 959-976.

[19] Gourieroux, C. (2004): "The Wishart Process for Stochastic Risk," forthcoming in Econometric Reviews.

[20] Gourieroux, C., and J., Jasiak (2001): "Memory and Infrequent Breaks", Economics Letters, 70, 29-41. 
[21] Gourieroux, C., Jasiak, J., and R., Sufana (2003): "The Wishart Autoregressive Process of Multivariate Stochastic Volatility," Working Paper, University of Toronto.

[22] Gourieroux, C., and A., Monfort (2005): "Econometric Specification of Stochastic Discount Factors", forthcoming in Journal of Econometrics.

[23] Gourieroux, C., Monfort, A., and V., Polimenis (2002) : "Affine Term Structure Models", Working Paper, CREST.

[24] Gourieroux, C., and C., Robert (2005): "Stochastic Unit Root Models", forthcoming in Econometric Theory.

[25] Gourieroux, C., and R., Sufana (2003) : "Wishart Quadratic Term Structure Models", CREF 03-10, HEC Montréal.

[26] Gourieroux, C., and R., Sufana (2004) : "Derivative Pricing with Multivariate Stochastic Volatility", CREF 04-09, HEC Montreal.

[27] Grabbe, J. (1983) : "The Pricing of Call and Put Options on Foreign Exchange", Journal of International Money and Finance, 2, 239-253.

[28] Heath, D., Jarrow, R., and A., Morton (1992) : "Bond Pricing and the Term Structure of Interest Rates: A New Methodology for Contingent Claims Valuations", Econometrica, 60, 77-105.

[29] Heston, S. (1993) : "A Closed-Form Solution for Options with Stochastic Volatility with Applications to Bond and Currency Options", Review of Financial Studies, 6, 327-343.

[30] Hilliard, J., and J., Reis (1998) : "Valuation of Commodity Futures and Options Under Stochastic Convenience Yields, Interest Rates and Jump Diffusion in the Spot" Journal of Financial and Quantitative Analysis, 33, 61-86.

[31] Jarrow, R. (1987) : "The Pricing of Commodity Options with Stochastic Interest 
Rates", Advances in Futures and Options Research, 2, 19-45.

[32] Jarrow, R., and S., Turnbull (1998) : "A Unified Approach for Pricing Contingent Claims on Multiple Term Structures", Review of Quantitative Finance and Accounting, 10, 5-19.

[33] Jarrow, R., and S., Turnbull (2000) : "The Intersection of Market and Credit Risk", Journal of Banking and Finance, 24, 271-299.

[34] Martellini, L., and P., Priaulet (2001) : "Fixed-income Securities", John Wiley \& Sons.

[35] Merton, R. (1973) : "An Intertemporal Capital Asset Pricing Model", Econometrica, $41,867-887$.

[36] Miltersen, K., and E., Schwartz (1998) : "Pricing of Options on Commodity Futures with Stochastic Term Structures of Convenience Yields and Interest Rates", Journal of Financial and Quantitative Analysis, 33, 33-59.

[37] Nielsen, L., and J., Saa Requejo (1993) : "Exchange Rate and Term Structure Dynamics and the Pricing of Derivative Securities", Working Paper, INSEAD, Fontainebleau.

[38] Ramaswamy, K., and S., Sundaresan (1985) : "The Valuation of Options on Futures Contracts", Journal of Finance, 40, 17, 1319-1340.

[39] Schwartz, E. (1997) : "The Stochastic Behavior of Commodity Prices: Implications for Valuation and Hedging," Journal of Finance, 52, 923-973.

[40] Yao, Y. (2001) : "State Price Density, Esscher Transform and Pricing Options on Stocks, Bonds and Foreign Exchange Rates", North American Actuarial Journal, 5, 104-117. 


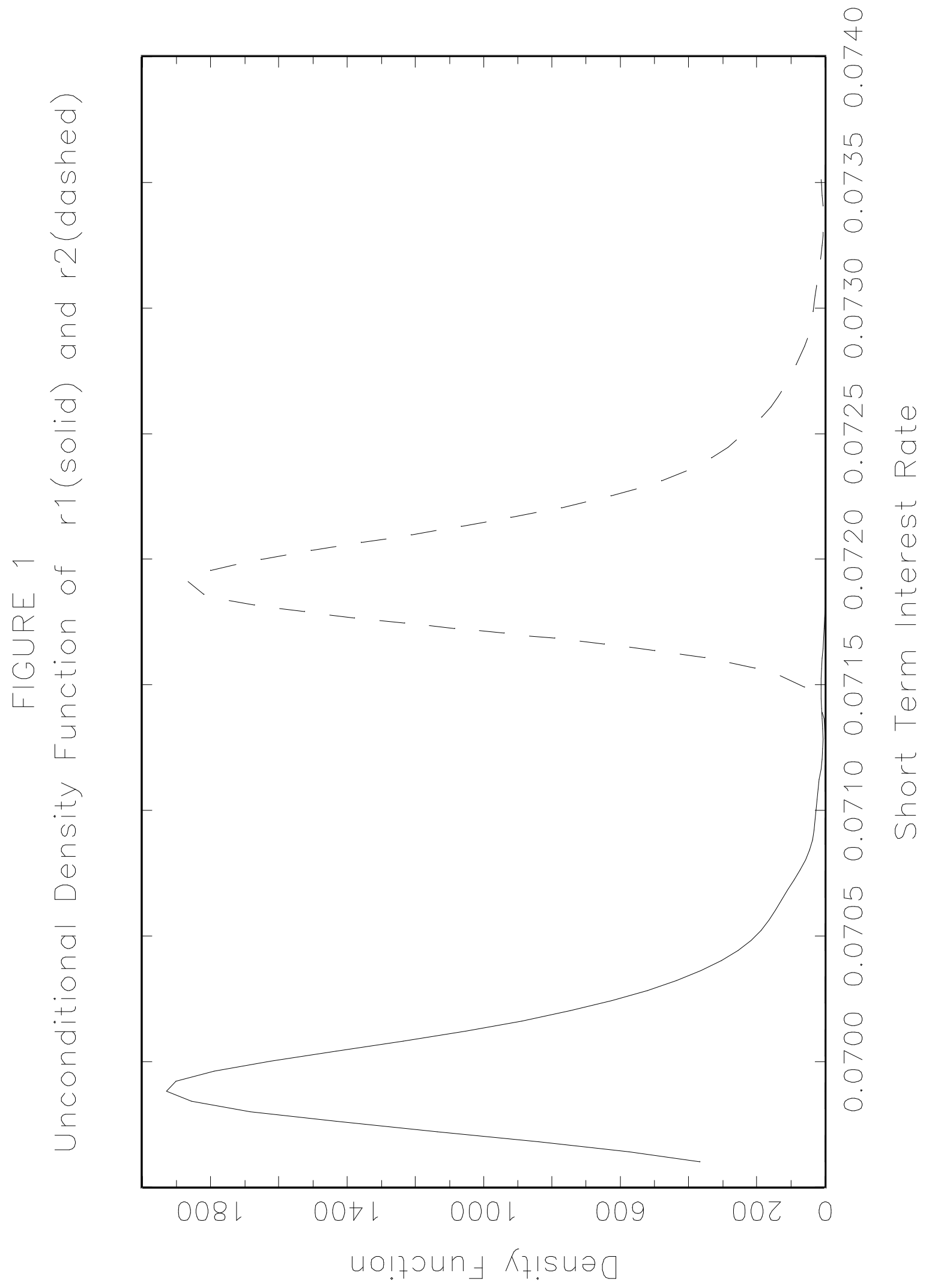




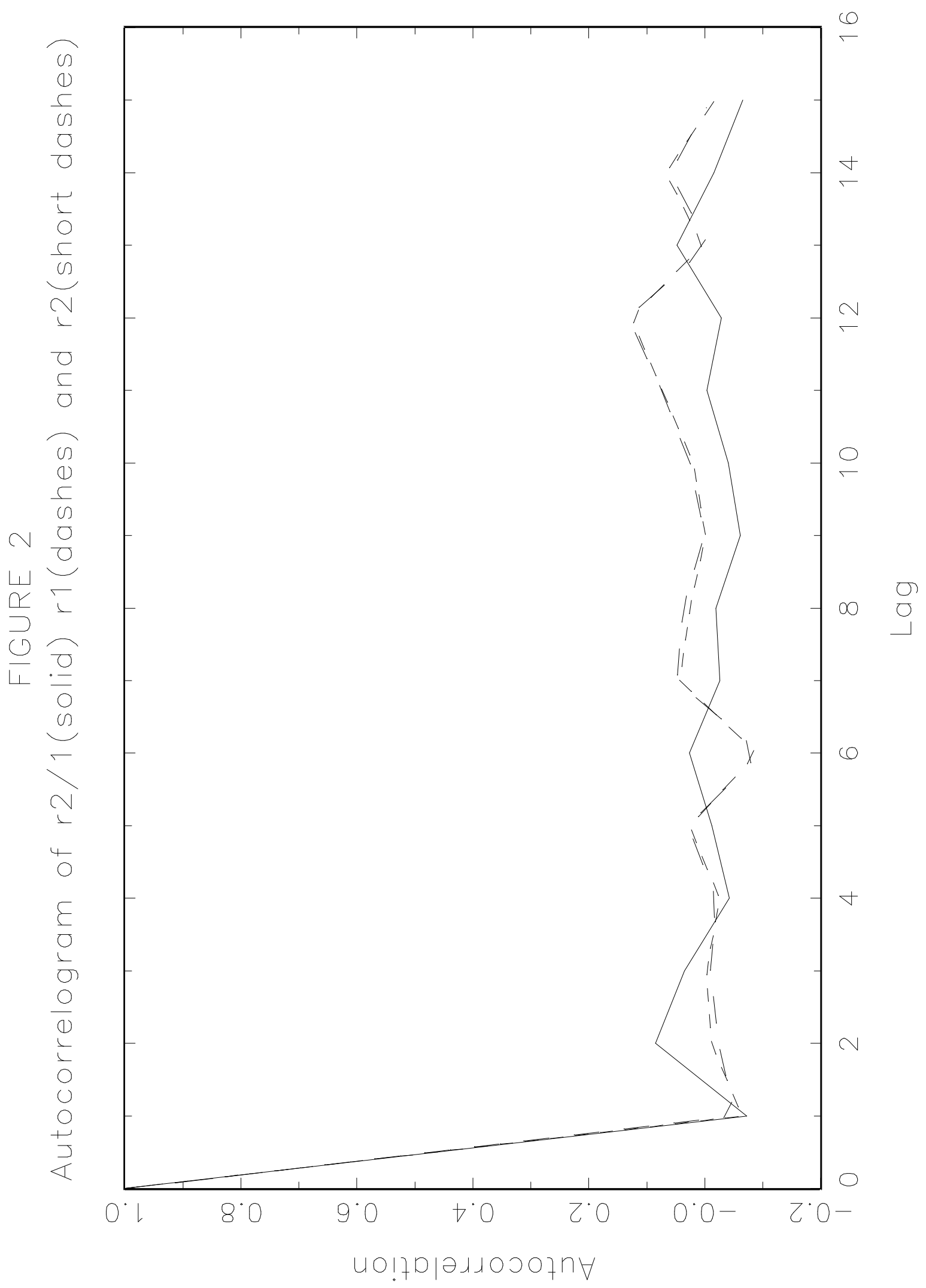




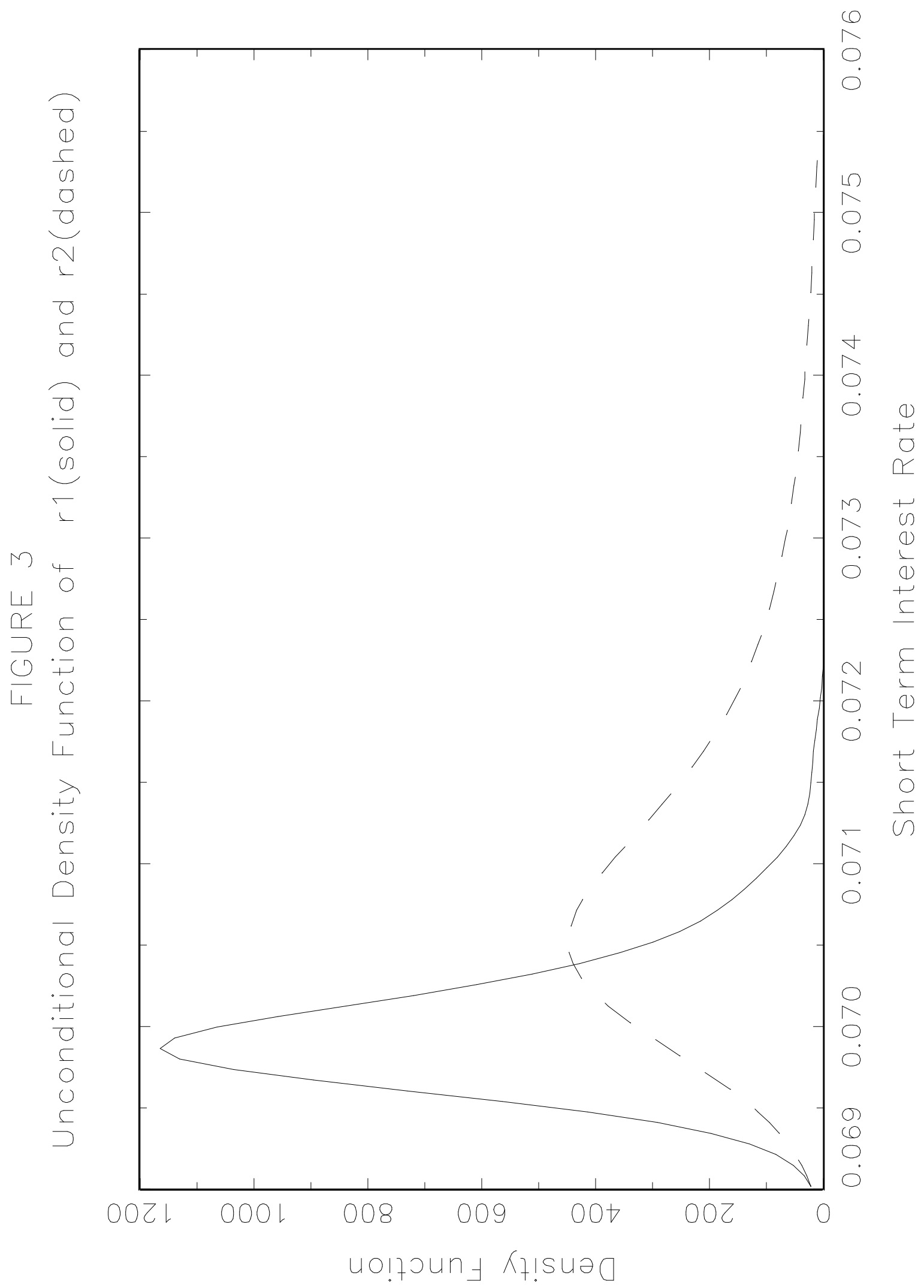




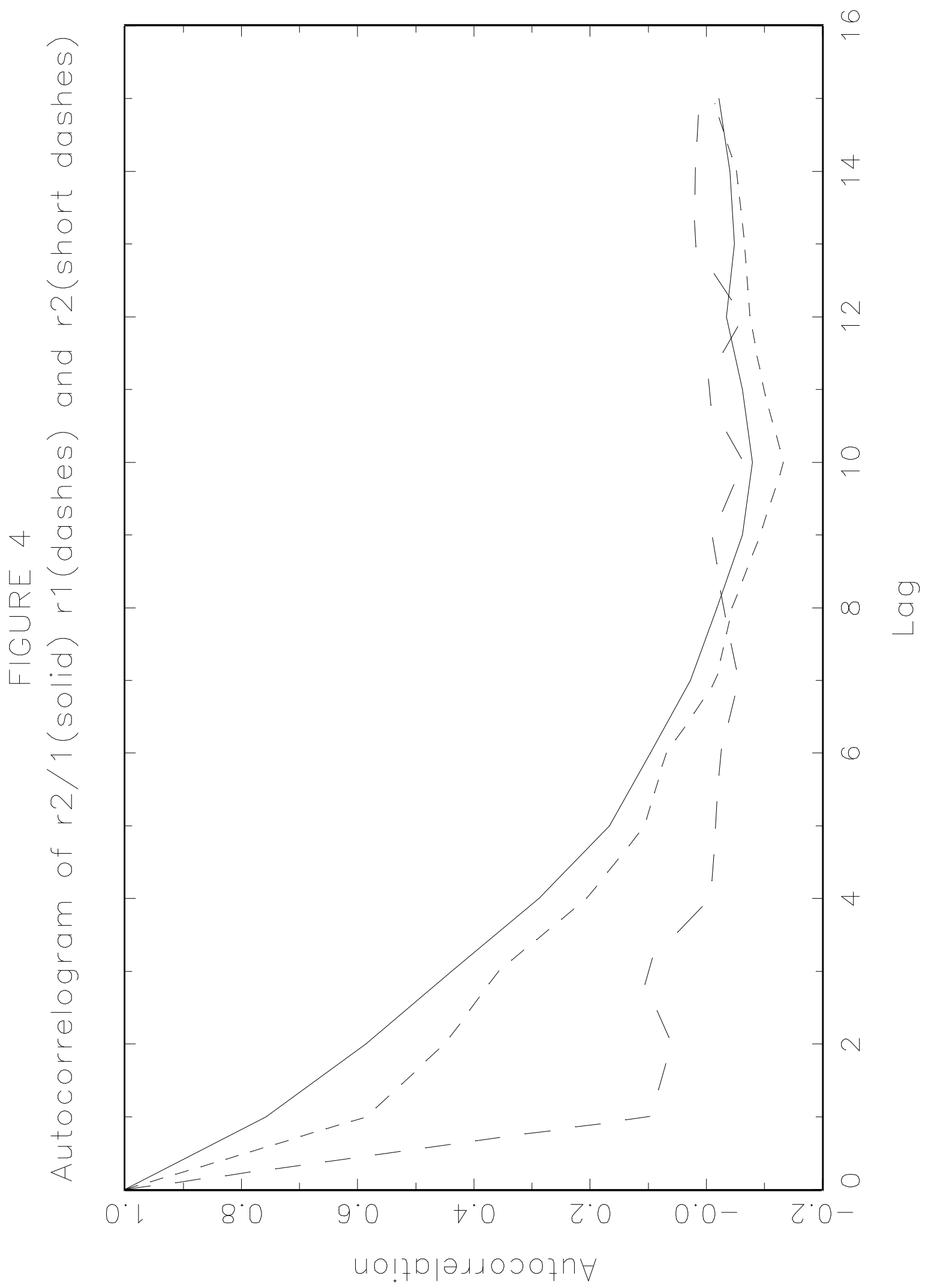




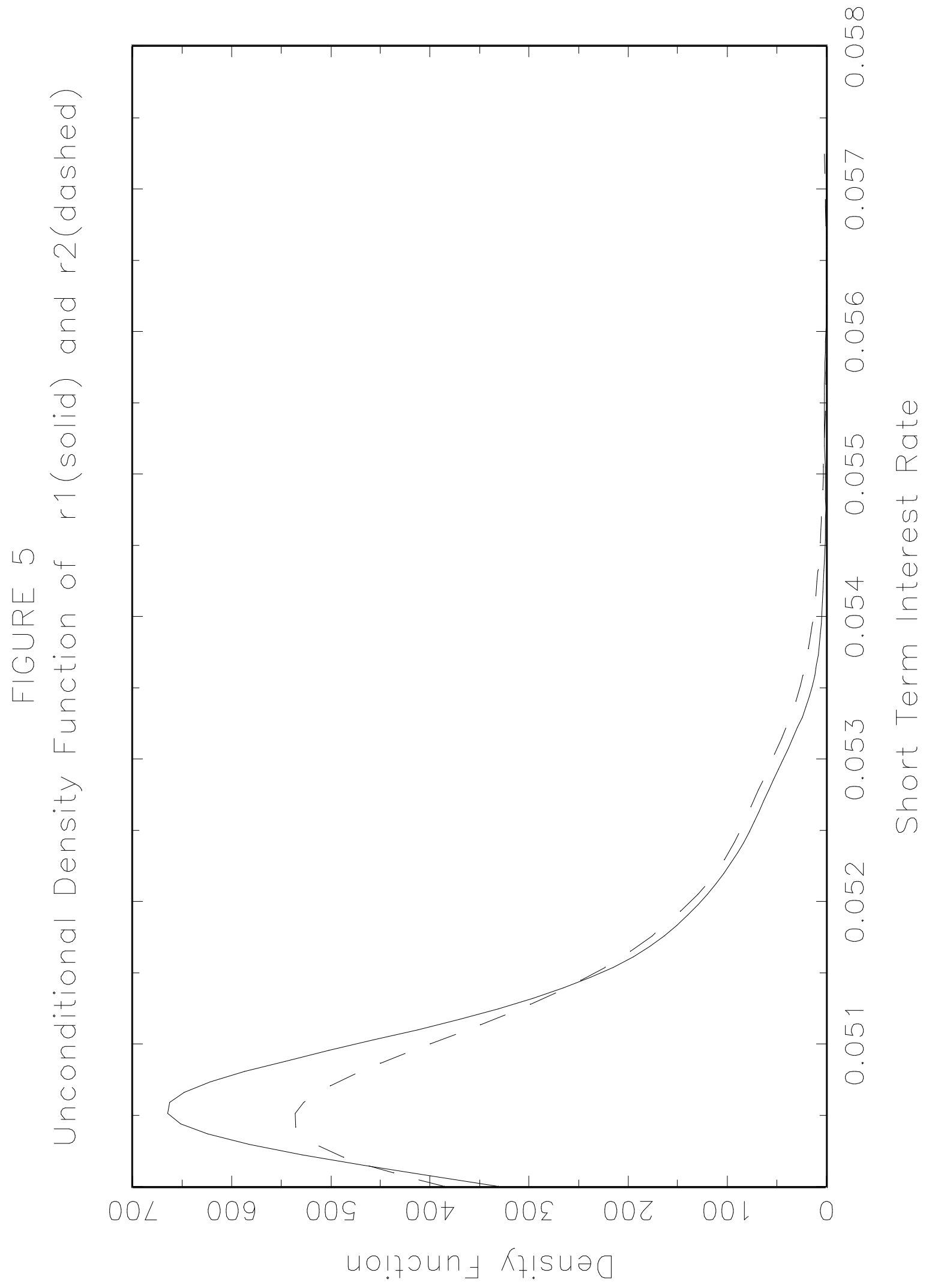




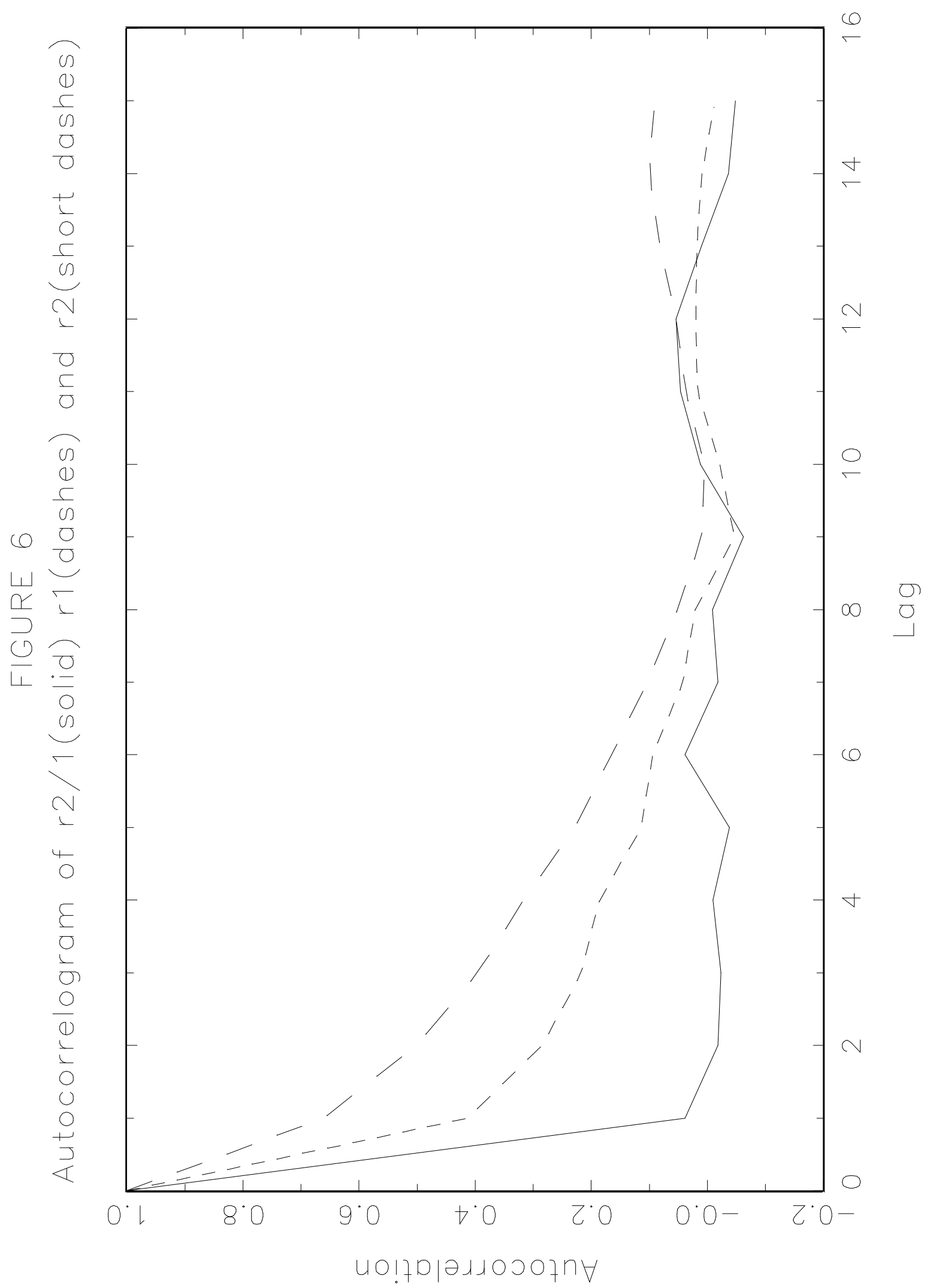




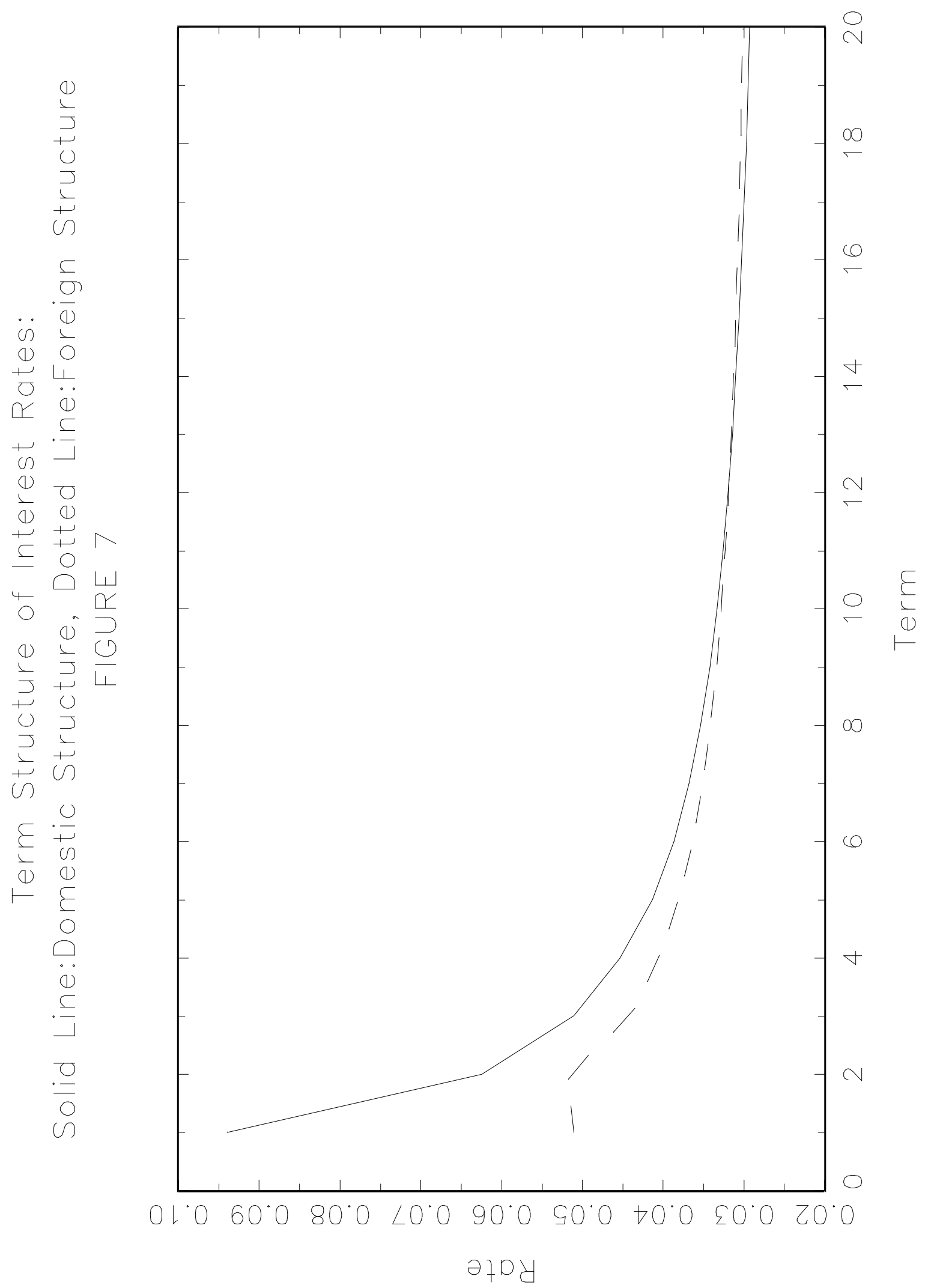




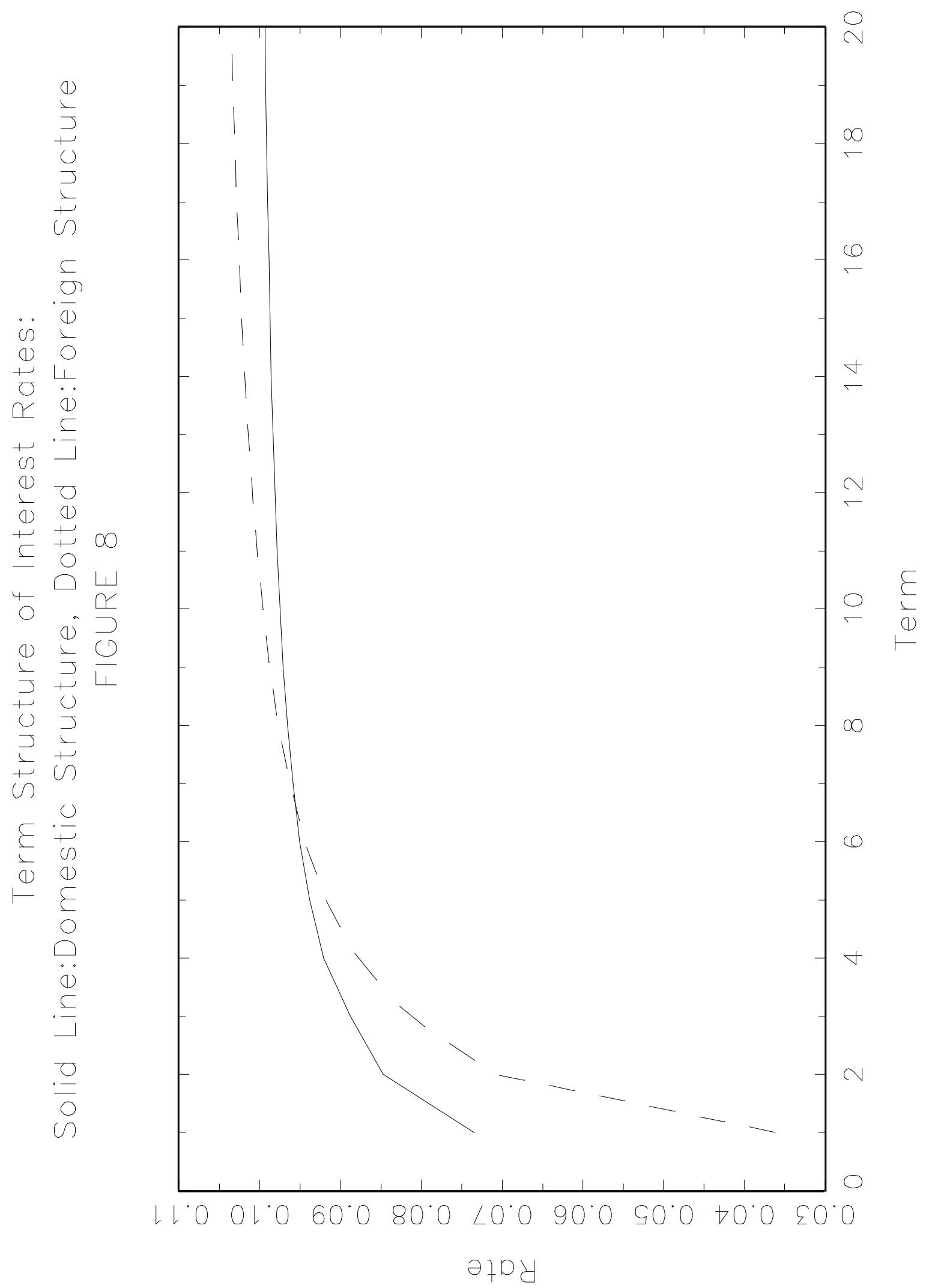




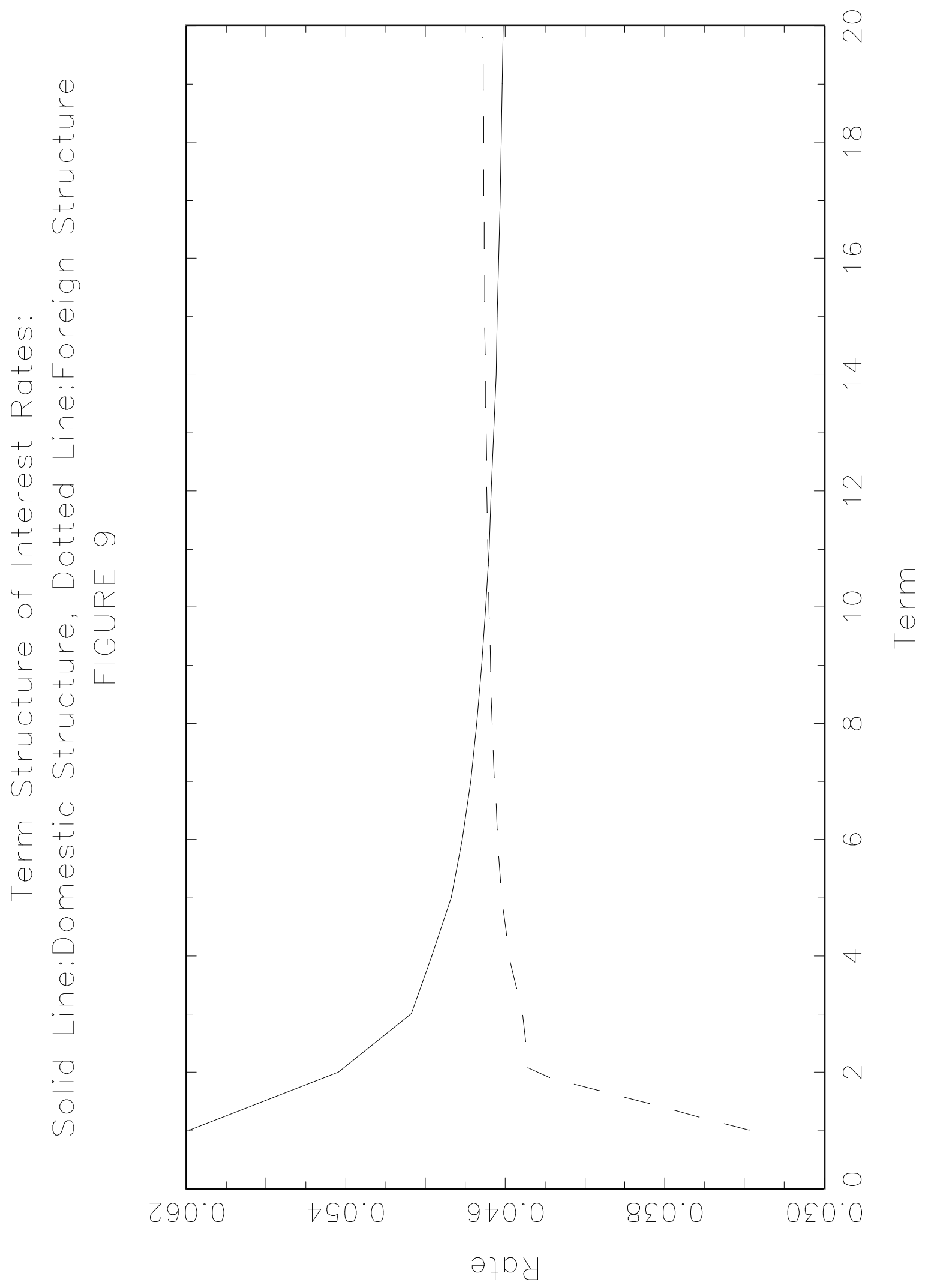




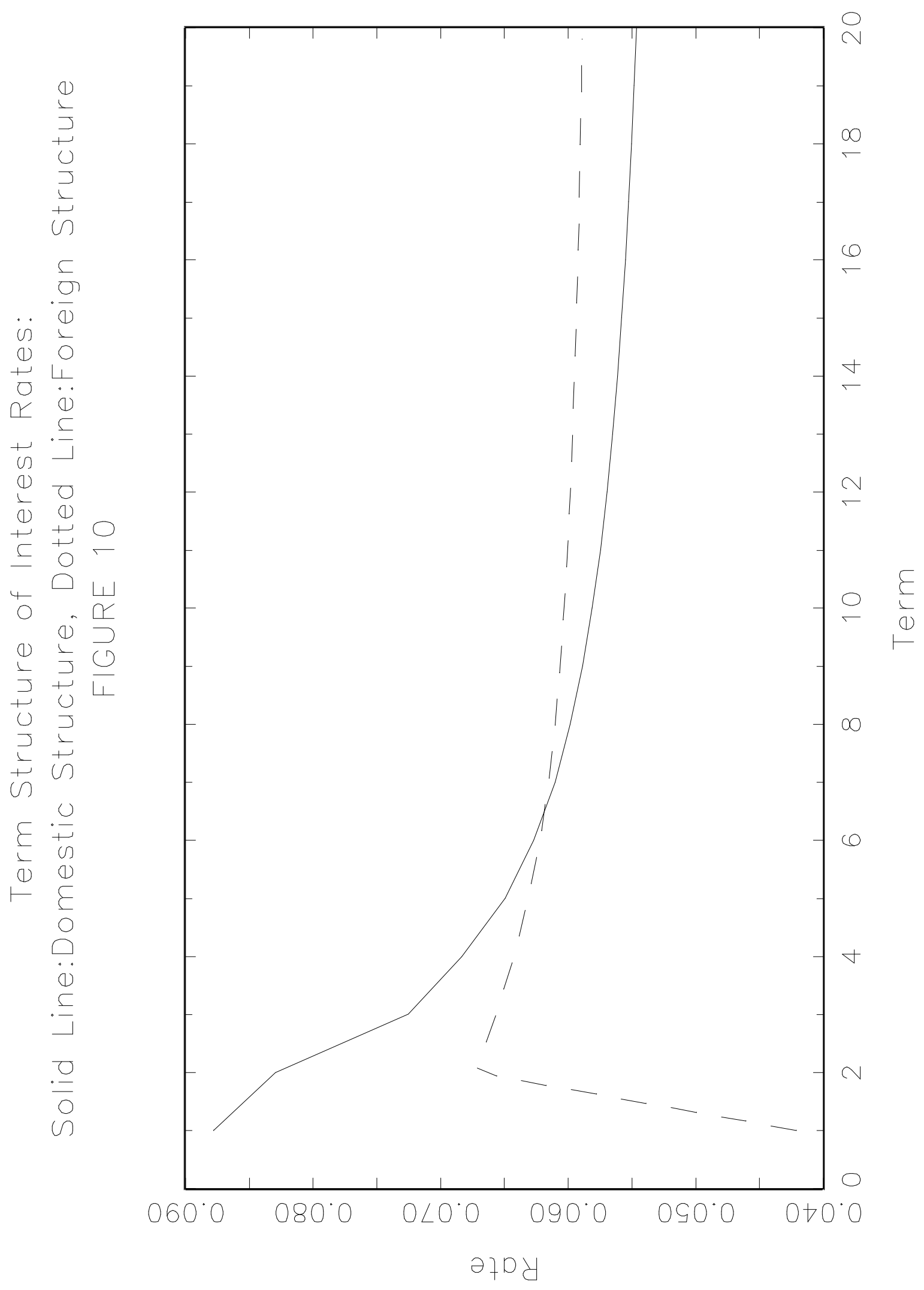

